\title{
Cracking the context-specific PI3K signaling code
}

2

3

4

5

6

7

8

9

10

11

12

13

14

\author{
Ralitsa R. Madsen1,*, Bart Vanhaesebroeck1,* \\ 1UCL Cancer Institute, Paul O'Gorman Building, University College London, 72 \\ Huntley Street London WC1E 6DD, UK \\ *Correspondence: r.madsen@ucl.ac.uk orbart.vanh@ucl.ac.uk
}

\begin{abstract}
Specificity in signal transduction is determined by the ability of cells to 'encode' and subsequently 'decode' different environmental signals. Akin to a computer software, this 'signaling code' governs context-dependent execution of cellular programmes through modulation of signaling dynamics and can be corrupted by disease-causing mutations. Class IA phosphoinositide 3-kinase (PI3K) signaling is critical for normal growth and development and is dysregulated in human disorders such as benign overgrowth syndromes, cancer, primary immune deficiency and metabolic syndrome. Despite decades of PI3K research, understanding of context-dependent regulation of the PI3K pathway and of the underlying signaling code, remains rudimentary. Here, we review current knowledge about context-specific PI3K signaling and how technological advances now make it possible to move from a qualitative to a quantitative understanding of this pathway. Insight into how cellular PI3K signaling is encoded/decoded may open new avenues for rational pharmacological targeting of PI3Kassociated diseases. The principles of PI3K context-dependent signal encoding/decoding described here are likely applicable to most, if not all, major cell signaling pathways.
\end{abstract}




\section{AN OVERVIEW OF CLASS IA PI3K RESEARCH}

Class IA phosphoinositide 3-kinase (hereafter PI3K) enzymes catalyze the formation of the second messenger phosphatidylinositol-3,4,5-trisphosphate (PIP3). This phospholipid triggers a central signaling pathway in eukaryotic cells that regulates various downstream effectors including protein kinases, such as AKT and mTORC1, and transcription factors belonging to the FOXO family1 (Fig. 1). The PI3K pathway is best known for its ability to coordinate anabolic metabolism and cell growth downstream of multiple growth factor receptors, including but not limited to those for insulin, insulin-like growth factor (IGF), vascular endothelial growth factor (VEGF), epidermal growth factor (EGF) and plateletderived growth factor (PDGF). PI3K family members with disease-associated mutations include PI3K $\alpha$ (encoded by the PIK3CA gene) and PI3K $\delta$ (encoded by the PIK3CD gene)1, which show ubiquitous or leukocyte-enriched expression, respectively (Fig. 1).

PI3K enzymatic activity was discovered 30 years ago2, and the two decades that followed were focused on fundamental PI3K research. The 1990s saw the discovery of multiple PI3K isoforms and key components of canonical PI3K signaling, linking the activity of this pathway with control of essential cellular processes3,4. At the turn of the millennium, the first mouse models with disrupted PI3K activity demonstrated that several components of this pathway are required for organismal homeostasis and normal development5. In addition, the PI3K $\alpha$ isoform was found to be among the most commonly mutated oncogenes in solid tumors, while the gene encoding the PIP3 phosphatase PTEN emerged as one of the most frequently inactivated tumor suppressors, superseded only by TP53 (Ref.6,7). The third decade of PI3K research has been dominated by the development and testing of PI3K pathway inhibitors as potential therapeutics for cancer and immune dysfunction. While the field has recently witnessed the approval of some PI3K inhibitors for clinical use, most of these compounds have failed to meet the initial high expectations, their utility in cancer treatment limited by systemic toxicity and/or tumor 
1 drug resistance1. However, some of these drugs have shown remarkable promise in the

2 treatment of genetic disorders of PI3K dysregulation, including PIK3CA-related overgrowth

3

4

5

6

7

8 spectrum (PROS) when used at a lower dose than in cancers and in the activated PI3K $\delta$ syndrome (APDS)9.

While the key PI3K pathway components have now been identified, a fundamental gap in our understanding of PI3K signaling concerns how different cell and environmental contexts determine the functional outcome of pathway activation. It remains unclear how activation of the same set of components can trigger the vast repertoire of PI3K-driven phenotypic responses, that may be glucose uptake and proliferation in one setting, or senescence and even cell death in others. Moreover, the impact of mutational activation of the PI3K pathway on its signaling dynamics is largely undetermined.

With inspiration from progress made in the field of RAS/ERK signaling, this review summarizes emerging evidence supporting the importance of a context-specific PI3K signaling 'code', governed by distinct dynamics of pathway activation. Additional research in dynamic PI3K signaling may allow us to better understand how it controls normal physiology, how it becomes corrupted in diseases such as cancer or insulin resistance, and how it can be modulated by pharmacological targeting.

EXAMPLES OF DYNAMIC INFORMATION TRANSMISSION IN CELL

\section{SIGNALING}

\section{Dynamic signal encoding and decoding}

Cell signaling represents an information transmission problem reflected in the need to obtain reliable information about the environment. To sense changes in external or internal conditions, a cell needs mechanisms to encode these changes and subsequently to decode them into an appropriate response. For any individual hormone or growth factor signaling response, 
1 there is no single protein or gene that preserves signaling specificity; instead, this is achieved

2 through dynamic regulation of multiple signaling effectors 10, hereafter referred to as 'dynamic

3 information transmission' (Fig. 2A-D). Accordingly, a cell's computational capacity - its

4 ability to receive and process diverse signals - is determined by the intrinsic biochemical

5 properties of its signaling components, including reaction rates, affinity constants, relative

6 expression levels and the presence of allosteric modulators 11,12. Cell-specific differences in one

7 or several of these parameters may lead to different and even opposite phenotypes downstream

8 of the same upstream stimulus 13.

While dynamic information transmission ensures that cells are capable of appropriately detecting, responding to and even memorizing a stimulus, the complexity is difficult to capture experimentally and calls for high-density time course studies, of single cells and multiple signaling effectors. In general terms, researchers interested in controlled perturbation of signaling dynamics first need to identify a system that allows direct manipulation of the input signal under study, alongside high-resolution monitoring of relevant output responses. Advances in synthetic biology have led to the development of several solutions, including chemically-induced dimerization (CID) and optogenetic systems, which enable extrinsic control of both temporal and spatial dynamics of signaling pathways (reviewed in Ref.14). Key limitations of these technologies include the need for genetic manipulation of cells to express the synthetic protein controllers alongside additional fluorescent reporters necessary for live single-cell imaging. Finally, conceptualisation of the obtained multidimensional data typically requires the generation of reliable and testable computational models that can predict the dynamic 'input-output' response for a given pathway 10,11. 

cells to respond to a wide range of external and internal perturbation by using only a limited repertoire of genetically-encoded circuits15,16.

Studies on the RAS/ERK signaling pathway have been instrumental in demonstrating key aspects of dynamic information transmission in cultured mammalian cell lines and model organisms. Early experiments in the rat PC12 pheochromocytoma cell line by the groups of Phillip Cohen and Chris Marshall revealed that transient activation of extracellular-regulated kinase (ERK) by EGF promotes cell proliferation whereas sustained ERK activation by neural growth factor (NGF) triggers cell differentiation17,18. A systematic study of the EGF-ERK cascade in the human MCF10A mammary breast epithelial cell line demonstrated that the concentration of extracellular EGF becomes encoded in temporal parameters such as the frequency and pulse duration of downstream ERK activation 19. In turn, different patterns of ERK activity are integrated and decoded by its effectors to control the cell's propensity to enter the cell cycle19. This study also showed that ERK activity remains pulsatile, even in the presence of continuously high EGF levels in the medium, establishing frequency modulation (FM) as an important mode of information transmission in this pathway 19. In other words, the breast epithelial cell encodes the growth factor dose in the frequency and duration of ERK activity pulses 19 .

\section{Organismal impact of ERK frequency modulation}

More direct evidence for the in vivo importance of ERK frequency modulation is now emerging. Using a light-inducible ERK activation system, it was recently demonstrated that different patterns of ERK signaling orchestrate distinct cell fate decisions in the fly embryo, in a region-specific manner20. Similarly, ERK frequency modulation has been linked to cell fate 
1 specification in C. elegans21. These are prime examples of how activation of the same pathway,

2 by using different signaling patterns, can specify distinct biological outputs.

4 Corrupted signaling dynamics downstream of RAS/ERK oncogenic mutations

5 The concept of corrupted signaling dynamics downstream of cancer-associated mutations

6 is not new11, but direct experimental evidence has only emerged in the last decade. In a seminal

7 study, Bugaj et al. used optogenetic stimulation of RAS to demonstrate that altered dynamic signal transmission properties, and thus not only a high level of baseline activation, contribute to the oncogenic properties of specific BRAF mutations (Fig. 2E)22. Rather than causing a constitutively "ON" state, some oncogenic BRAF mutations still allow the pathway to perceive upstream signals. However, the decay kinetics of downstream ERK phosphorylation is slower in cells expressing mutant BRAF compared to wild-type counterparts, which leads to loss of fidelity in signal transmission and an aberrant phenotypic response (Fig. 2E)22. Furthermore, the BRAF inhibitors Vemurafenib and SB590885 enhance downstream ERK signaling by corrupting the dynamic signal transmission properties of the system: instead of the normally rapid ERK signal decay when RAS signaling ceases, these BRAF inhibitors result in slow pathway deactivation and cellular misinterpretation of the original input signal (Fig. 2E)22.

These findings have potential therapeutic implications by suggesting that it might be necessary for drug treatment to shift away from complete inhibition of the mutated components and instead explore how normal signaling dynamics can be restored23, possibly by modulating the relevant upstream regulators24. This is consistent with previous computational and experimental testing of the overall concept that signaling dynamics may serve as a pharmacological target13.

\section{Other signaling pathways}


1 In addition to the RAS/ERK module, dynamic information transmission has been

2 demonstrated for other signaling pathways including DNA damage-induced TP53 activation25,

$3 \mathrm{NF}-\kappa \mathrm{B}$ regulation in innate immune signaling26,27, Ca2+-regulated NFAT28,29, developmental

4 TGFß/NODAL30-33, WNT34, SHH35,36 and $\mathrm{NOTCH}_{37-39}$ signaling, and, as will be detailed

5 below, PI3K-dependent insulin signaling 40,41. In contrast to most other pathways, however, our

6 understanding of the dynamics of the PI3K pathway remains relatively crude. This is in part

7 due to limited experimental options for selectively varying individual features such as the

8 strength and duration of activation of an enzyme and to overcome complex feedback signaling 9 loops.

\section{EVIDENCE FOR A DYNAMIC PI3K CODE}

Given the many parallels between the RAS/ERK and PI3K pathways, including their frequent activation in cancer, dynamic information transmission would be expected to assume similar importance in determining PI3K-based phenotypic output, in both health and disease. PI3K signaling is commonly depicted in static maps of varying complexity as new effectors and modulators are identified (Fig. 1). These conventional PI3K signaling maps may give the false impression of a hard-wired circuit, with identical output irrespective of context. In reality, PI3K pathway activation can be associated with diverse and even opposite phenotypes, including cell growth, senescence, proliferation and cell death. At the organismal level, disease-causing mutations in this pathway may promote cancer in one tissue and benign overgrowth in another42. In short, the phenotypic output of PI3K signaling is remarkably flexible, governed both by dynamic activation, cell type-specific gene expression and changes in the microenvironment, as will be detailed below. 
2 PI3K signaling was provided 20 years ago. Using HepG2 liver cells stimulated with PDGF, the

Kazlauskas group demonstrated the presence of early (0-1h post-stimulation) and late (3-7h post-stimulation) waves of PI3K activity, with the second PI3K wave being essential for induction of DNA synthesis and cell cycle progression43. In 2002, Tengholm and Meyer suggested the existence of an insulin-specific PI3K signaling code to explain the translocation of cytosolic GLUT4 glucose transporters to the plasma membrane of 3T3-L1 adipocytes upon stimulation with insulin but not with PDGF (Fig. 3)44,45. Their data suggested that strong but transient activation of PI3K triggered by PDGF fails to elicit a response because the integrated concentration of $\mathrm{PIP}_{3}$ over time remains below a cell-specific threshold for downstream GLUT4 translocation (Fig. 3)44. In the same year, Sedaghat et al. published the first computational model of metabolic insulin signaling, demonstrating how mathematical approaches can be used to capture pathway complexity and as hypothesis-generating tools for known and unknown signaling mechanisms46. Subsequently, several other models of PI3K signaling, with a particular focus on AKT and mTOR regulation, have emerged, differing with respect to time scale and network complexity (for a review of mTOR models, see Ref.47). There is also an increasing appreciation that temporal and spatial regulation need to be considered jointly48, especially when it comes to understanding the exact dynamics and thresholds of pathway activation that are required to control metabolic versus mitogenic outputs49.

The discovery that growth factor-induced PI3K signaling exhibits a dynamic pattern of activation during the cell cycle suggested that constitutive PI3K activation might lead to cell cycle abnormalities 43 as observed by Klippel et al. upon overexpression of constitutively-active PI3Ka50. In line with these observations, the Carrera group demonstrated that temporal PI3K downregulation during the cell cycle is important for increased downstream FOXO1 activity at the time when this transcription factor is necessary for cell cycle completion51. In a 
1 subsequent study, the cell cycle block could be avoided by ensuring near-endogenous levels of

2 expression of the constitutively-active PI3Ka52. A separate study focusing on cells with

3 transient overexpression of constitutively-active AKT also reported cell cycle abnormalities,

4 linked to dysregulated activation and localisation of the AKT substrate CDK2 (Ref.53), a

5 mechanism that was also suggested by the first studies of this phenomenon by Klippel et al.50.

6 Subsequent findings have highlighted that these effects are likely to be context-dependent and

7 thus vary both as a function of cell type and culturing conditions54-56. Overall, the take-home

8 message from these studies is that the temporal pattern of PI3K activation influences the

9 dynamics of the mammalian cell cycle, with biological output determined both by cell-intrinsic

10 and -extrinsic factors.

Renewed interest in the dynamic PI3K code

With advances in automated liquid handling systems and '-omics' technologies, more systematic studies of the mechanisms whereby cells decode different patterns of PI3K activation have begun to emerge. By combining experiments in the rat pheochromocytoma PC12 cell line with mathematical modeling and concepts from electrical engineering, the Kuroda group offered a detailed characterisation of AKT signaling dynamics in response to EGF stimulation57 (Fig. 4A). A functionally-coupled signaling response downstream of EGFR was observed for activation of AKT, meaning that the relative magnitude of the upstream stimulus and the downstream response followed the same pattern (Fig. $\mathbf{4 A})$. This contrasted with the decoupled downstream signal transmission to mTORC1 and S6 kinase (S6K)(Box 1); in other words, S6 phosphorylation occurred most potently in response to weak, sustained EGFR activation, with the pathway effectively filtering out strong but transient signaling events (Fig. 4A)57. It remains to be determined whether this decoupling has physiological relevance, but the authors speculate that it may ensure that S6-dependent ribosome and protein 
1 biosynthesis take place only when the upstream signal is of sufficient duration, thus limiting

2 potential waste of cellular energy57. Given the possibility that additional PI3K/AKT-

independent inputs may impinge on mTORC1 and S6 regulation in different contexts, further systematic studies are also needed to determine the potential contribution from such crosstalk. Physiologically, the pancreas secretes insulin at a low constant level and in a 10-15 minute pulsatile manner, with additional insulin secretion in response to eating58,59. By providing different patterns of insulin stimulation in the rat hepatoma FAO cell line in vitro and in anesthetized rats in vivo, the Kuroda group demonstrated that insulin dynamics are captured differently by AKT and its downstream effectors as a result of differences in feedback regulation and kinetic constants (Fig. 4B)40,60. Whereas phosphorylation of S6 kinase (S6K) was most responsive to an increase in the rate of insulin exposure, and was thus used by the cell to detect transient stimulation, it always returned to the same basal level, regardless of stimulus duration or dose, a phenomenon known as 'perfect adaptation'. Insulin dose and duration were better captured in the dynamics of GSK3 $\beta$ phosphorylation and glucose 6phosphatase (G6P) transcription40,60. Similar dynamic information transmission has also been demonstrated in insulin-stimulated mouse 3T3-L1 adipocytes41. These findings may have important physiological implications if future studies demonstrate that dynamic signal encoding and decoding is needed for insulin-responsive tissues to elicit an appropriate metabolic response to different physiological patterns of the hormone.

The dynamics of PI3K activation are also important during B-cell selection in early development where both hyper-responding, and potentially self-reactive, cell clones, as well as clones with poor response to antigen activation undergo negative selection. Low PI3K signaling occurs in poorly-responsive cells, whereas strong PI3K activation characterises autoreactive immune cells61. Accordingly, pre-B cell negative selection takes place both when 
1 PI3K signaling falls below a certain lower threshold and when it exceeds an upper threshold of

2 hyperactivation62.

It is important to emphasise that the PI3K code does not exist in isolation and is subject to extensive crosstalk with other pathways. For instance, a quantitative study of NGF signaling in PC12 cells revealed that the cellular decision to differentiate or proliferate is determined by a two-dimensional phospho-ERK/phospho-AKT response map that integrates the activation strength of both pathways63. It has also been demonstrated that the early and late dynamics of FOXO3 nuclear-cytoplasmic shuttling is differentially-regulated by AKT and ERK downstream of different growth factors, potentially serving as a mechanism to encode the identity of upstream ligands64.

Lastly, the PI3K code is likely to depend on the spatial distribution of the PIP 3 and $\mathrm{PI}(3,4) \mathrm{P}_{2}$ lipid products of $\mathrm{PI} 3 \mathrm{~K}$ activation. For example, only $\mathrm{PI}(3,4) \mathrm{P}_{2}$ appears to move from the plasma membrane to early endosomal comparments where it results in preferential activation of AKT2 over other isoforms65. Future studies are warranted to determine the extent to which spatiotemporal control of $\mathrm{PIP}_{3}$ and $\mathrm{PI}(3,4) \mathrm{P}_{2}$ is used to encode distinct cellular phenotypes.

\section{Technological challenges and potential solutions}

A quantitative understanding of the dynamic PI3K signaling code requires 'forward' experimental testing, using tools that allow precise control of PI3K activation. Several artificial systems have already been developed for this purpose (Fig. 5A,B), however none of these allow isoform-specific PI3K activation. Besides technical implementation, a remaining challenge is how best to quantify pathway dynamics, both at the level of PI3K activation and downstream responses. Current single-cell approaches rely on a limited set of PI3K signaling reporters (Fig. 5C,D) and thus fail to capture the potential existence of a range of effector-specific responses. 
1 The use of exogenously expressed biosensors is also not without caveats; the potential for

2 dominant-negative effects on signaling calls for careful optimization of expression levels and control for both false positives and false negatives66.

Potential solutions are in sight, however. These include: a) the use of CRISPR-mediated tagging of endogenous effector proteins, such as AKT or FOXO, to follow their dynamic translocation live and without stoichiometric changes; b) integration of quantitative, multiplexed immunofluorescence in time course studies that seek to assess a wider repertoire of signalling responses at the single-cell level67-69. Recent proof-of-concept studies from Peter Sorger and his team illustrate the detailed cell signaling insight that can be obtained with such some of these approaches - with clear evidence for translational potential64,70. Adoption of these methodologies will likely be instrumental in closing the PI3K signaling knowledge gaps that will be discussed next.

\section{EXAMPLES OF CONTEXT-DEPENDENT DIFFERENCES IN THE PI3K CODE}

\section{Differences in the PI3K code according to cell type}

The phenotypic outcome of PI3K activation changes according to cell type, reflecting intrinsic differences in the expression of signaling components and downstream effectors. As a result, the same pattern of PI3K pathway activation may lead to distinct responses in two different cell types under otherwise identical conditions. For instance, an adipocyte and a muscle cell differ in their response to insulin-dependent activation of the PI3K pathway. Both induce an anabolic programme, but according to different mechanisms - a muscle cell will predominantly engage protein synthesis and glycogen storage whereas an adipocyte's response will be biased towards lipid accumulation71. While this is an obvious example, differences are also likely to exist in otherwise similar cell types. For example, in their study of ERK- and AKT-dependent FOXO3 regulation, the Sorger laboratory used a panel of breast cancer cell 
1 lines and normal controls to demonstrate how differences in network topology result in cell

2 line-specific dynamics of FOXO3 nuclear-cytoplasmic translocation64.

PI3K signaling studies commonly use transformed cell lines or immortalized, nontumorigenic counterparts, whose signaling principles and phenotypic outputs cannot necessarily be extrapolated to those operating in untransformed cells which are more relevant for understanding normal regulation and mechanisms of early disease progression. Intrinsic biological differences across cell types and species are equally important to consider when evaluating oncogenic mechanisms, with early studies reporting different susceptibilities to transformation and senescence across different human cell lines as well as mouse versus human fibroblasts72,73. Oncogenic activation of PI3K signaling has also been shown to elicit senescence in some cellular contexts but not others62,74-81 - with species, cell lineage, expression of key tumor suppressors (for example, TP53, retinoblastoma protein) and the strength of PI3K activation emerging as important determinants.

A better understanding of cell type-specific PI3K signaling may also clarify the perplexing phenotypic complexity characterising diseases of PI3K dysregulation. For example, activating mutations in $\mathrm{PI} 3 \mathrm{~K} \alpha$ are frequent in epithelial cancers originating in ectodermal and endodermal tissue derivatives, but when the same mutations are acquired developmentally in mesodermal and neuroectodermal tissues, the common outcome is non-malignant overgrowth42.

\section{Differences in the PI3K code according to organismal and cell developmental stage}

There are emerging indications that the effect of PI3K $\alpha$ activation may also differ according to the developmental stage of the cells and the organism. Constitutive hyperactivation of the PI3K pathway has previously been linked to progenitor stem cell loss in mouse hematopoietic82,83, skeletal muscle84 and epidermal lineages80. Paradoxically, 
1 homozygous expression of the oncogenic PIK3CAH1047R variant delays tumor growth in the

2 epidermis of mice expressing the human papillomavirus (HPV) E7 oncogene80.

3 Mechanistically, homozygosity for PIK3CAH1047R promoted the differentiation of epidermal

4 progenitors downstream of increased phosphorylation of the AKT substrate SH3RF1, resulting

5 in disruption of its scaffolding function and ability to promote c-Jun N-terminal kinase (JNK)

6 signaling which is critical for maintenance of skin cell progenitors80.

In contrast, oncogenic PI3K pathway activation has been linked to long-term stemness in both mouse and human pluripotent stem cells (hPSC)85-89, which are used as models of the embryonic epiblast prior to gastrulation. Oncogenic $\mathrm{PI} 3 \mathrm{~K} \alpha$ activation downstream of PIK3CAH1047R can also induce multipotency in otherwise lineage-restricted, adult mammary epithelial cells in vivo90,91. The mechanistic basis of these observations remains limited, however. Computational network reconstruction and experimental follow-up suggest that homozygous expression of PIK3CAH1047R in hPSCs leads to signaling rewiring and selfsustained TGF $\beta$ pathway activation downstream of increased NODAL expression92. Nevertheless, these findings require further confirmation and may only apply to contexts conducive to embryonic gene expression such as hPSCs and transformed tumor cells93.

Overall, these observations suggest that developmental context, cell type and differentiation stage may interact to determine the specific response to PI3K activation. The exact dynamics of PI3K activation are likely modulators of this relationship. As mentioned above, chronic PI3K activation in hematopoietic stem cells (HSCs) causes their exhaustion, yet transient pathway activation in response to physiological stress or cytokine stimulation is associated with better HSC regeneration and long-term maintenance94. A similar phenotype has also been observed in skin adipocyte stem cells undergoing renewal95.

Clinical observations indicate that activating $\mathrm{PI} 3 \mathrm{~K} \alpha$ mutations in developmental overgrowth disorders known as PROS are more likely to have been acquired in progenitor stem 
1 cells as opposed to pluripotent embryonic stem cells or terminally-differentiated cell types42. It

2 is thus tempting to speculate that PI3K activation-induced negative selection/growth

3 suppression in specific progenitor cells during embryogenesis may underlie the apparent

4 absence of strongly-activating PI3K $\alpha$ mutations in hematopoietic and endodermal lineages in

5 such disorders42. Moreover, weaker PI3K $\alpha$ variants are tolerated in a wider tissue distribution42,

6 perhaps reflecting dose-dependent differences in negative selection downstream of chronic

$7 \quad$ PI3K activation.

Future studies are warranted to address these hypotheses, with careful consideration of

9 the contribution of non-cell-autonomous effects linked to tissue complexity and niche-specific

10 microenvironments in vivo. For instance, the relative strength of combined AKT and ERK

11 activation in endothelial cells - a commonly affected cell type in PROS patients - has been shown to balance the self-renewal and differentiation of mouse HSCs in vivo96. Consequently, chronic activation of AKT in endothelial cells promotes self-renewal of long-term hematopoietic stem and progenitor cells, whereas concomitant activation of ERK signaling opposes this effect by triggering the differentiation of HSCs96.

Differences in the PI3K code according to microenvironmental conditions

It is commonly stated that activation of the PI3K pathway leads to enhanced cell survival. However, this outcome depends on environmental context, with changes in nutrient, growth factor and oxygen availability able to modify the output of the PI3K code. Across a range of cell types, PI3K pathway activation enables survival under adverse conditions such as growth factor/serum removal97-101, UV-B irradiation102,103 and matrix detachment103,104. When cells are cultured in the presence of growth factors/serum, however, several studies have reported that oncogenic PI3K pathway activation does not confer additional resistance to cell death79,89,99. 
1 This finding suggests the existence of a PI3K activity threshold for survival, beyond which

2 additional activity offers little benefit.

Under other conditions, PI3K activation can even lead to cell death. Using an inducible

4 form of a constitutively-active $\mathrm{PI} 3 \mathrm{~K} \alpha$ in rat embryonic fibroblasts, Klippel et al. found that

5 prolonged pathway activation (48h) in the absence of serum results in apoptosis which could

6 be rescued by rapamycin50. Another study noted that strong overexpression of constitutively-

7 active viral Akt was not well-tolerated by a rat hippocampal cell line, whereas intermediate

8 levels of overexpression offered protection against apoptosis97. Due to increased energy

9 demand and reactive oxygen species generation 105, cells with chronic PI3K activation are also

10 sensitized to cell death under conditions of glucose deprivation 106,107, hypoxia108,109 and oxidative stress110-112, although this may depend on the pattern and strength of pathway activation110. The PI3K pathway also promotes death of necrotic hematopoietic and neuronal cells, giving rise to a seemingly paradoxical rescue of cell viability upon PI3K pathway inhibition113,114. A similar response was reported in a mouse epidermal cell line treated with the pro-apoptotic factor Fas115.

Microenvironmental conditions can also change as cells multiply and establish physical contacts with one another, coinciding with changes in the extracellular concentration of multiple factors. This, in turn, influences both the dynamics of and the response to PI3K activation, in ways that may not be revealed in conventional population-based cell studies. For example, breast epithelial MCF10A cells exhibit a bimodal distribution of PI3K $\alpha$ expression and AKT phosphorylation, subject to modulation both by cell density and the expression of oncogenic PI3K $\alpha$ variants78. Through Eph receptor activation, cell density has also been shown to modulate the spatial distribution of EGFR activity, with high densities resulting in selective suppression of downstream AKT activation116. Furthermroe, heterogeneity in the signaling 
1 response will also reflect intrinsic differences in protein expression within individual

2 cells78,117,118.

\section{IS THE PI3K CODE CORRUPTED WHEN THE PI3K PATHWAY IS MUTATED?}

5

A wealth of information is available on activating PI3K $\alpha$ and PTEN loss-of-function mutations when it comes to key phenotypes such as cancer growth, survival and metabolism. Yet, we know very little about whether these genetic alterations corrupt PI3K signaling dynamics and how such corruption of the code may contribute to the observed phenotypic changes. Given computational evidence that many cancer mutations are likely to result in dynamic and structural rewiring of signaling networks119, a better understanding of a putative "mutant" PI3K code is warranted.

Distinct PI3K $\alpha$ mutations differ in their potency to activate the pathway 120,121, and we have recently demonstrated that differences in allele dosage of PIK3CAH1047R cause striking, near-binary phenotypic differences in human pluripotent stem cells89. With evidence that corrupted signaling dynamics comprise a defining feature of oncogenic mutations in the RAS/ERK pathway22 (Fig. 2E), similar questions await to be addressed in relation to PI3K signaling. Are oncogenic mutations in the PI3K signaling pathway causing an amplitude increase in $\mathrm{PIP}_{3}$ - at baseline and/or in response to growth factors? Or are they (also) increasing signal duration following external stimulation? How do they affect the natural temporal dynamics of PI3K activation, and would such changes be sufficient to result in corrupted information transmission within the cell? Do oncogenic PIK3CA mutations give rise to mutant p110 $\alpha$ proteins with an altered subcellular localisation and spatial dynamics of PI3K signaling? Are differences in spatiotemporal signaling dynamics important determinants of the phenotypic variability observed across different mutations in vivo and across different doses of the same 
mutation? How might disease-associated changes to the dynamic PI3K signaling code be

shaped by the cell type and its microenvironment?

Some evidence that constitutive activation of PI3K alters the cellular decoding of growth factor stimulation was provided by Klippel et al. in their study of rat embryo fibroblasts constitutively expressing membrane-targeted forms of PI3K $\alpha$ or AKT50. Subsequently, the Sorger group's work on AKT- and ERK-dependent control of FOXO3 was the first - and remains the only - study to touch upon this complexity in a systematic manner. Although the study does not extend to cellular decision making, it demonstrates that oncogenic PIK3CA mutations reduce the dynamic range over which $\mathrm{FOXO} 3$ can respond to growth factors in human breast cancer cell lines64. Thus, similar to the discovery of corrupted information transmission in cancer cells with oncogenic BRAF mutations (Fig. 2E)22, cells with activating PI3K $\alpha$ mutations may exhibit low-fidelity transmission of upstream signals.

The benefits of efforts to capture this complexity extend beyond the realms of oncology. The questions above are equally relevant for our understanding of diseases such as APDS and PROS. As alluded to by Kubota et al., insight into pathological changes to PI3K signaling dynamics may also contribute to a better understanding of the phenomenon of selective insulin resistance where only insulin-dependent glucose regulation but not lipid or protein synthesis is compromised 60.

\section{THE CONTEXT-DEPENDENT PI3K CODE: A CHALLENGE AND AN} OPPORTUNITY FOR THERAPEUTIC TARGETING

Multi-level pathway dynamics and limited therapeutic success of PI3K targeting in cancer

BRAF inhibitors can corrupt the signaling dynamics of the RASERK pathway in cultured cells, resulting in its paradoxical activation and loss of signaling fidelity akin to that observed with specific oncogenic BRAF mutations22 (Fig. 2E). Similarly, the EGFR inhibitor lapatinib 
1 can lead to a paradoxical increase in S6 phosphorylation in rat pheochromocytoma cells (Fig.

2 5A)57. Such findings of unexpected pathway rewiring illustrate an important limitation in

3

4

5

6 conventional thinking about pharmacological targeting of disease-associated signaling pathways. In cancer, the most common approach relies on a priori predictions about the right dosing regimen122. At present, such predictions are mainly founded in the belief that effective disease management can be achieved through direct pharmacological manipulation of one or several molecular targets identified through genomic sequencing efforts.

Therapeutic targeting of cancers with mutational PI3K pathway hyperactivation is commonly based on continuous high-dose inhibitor administration (often the so-called maximum-tolerated dose defined in phase I clinical trials). This strategy has so far had limited success in cancers associated with PI3K mutations, and is further compromised by adverse effects due to on-target PI3K inhibition in normal tissues123. Hyperglycemia, in particular, is a major problem because it feeds back to the pancreas to trigger rapid insulin secretion, which in turn activates the PI3K pathway and counteracts drug-induced PI3K inhibition 124.

Beyond toxicity and systemic feedback, pharmacological inhibition of PI3K signaling is also dampened by cell-intrinsic adaptive and acquired resistance, rooted in the context-specific properties of the PI3K code. For example, negative feedback regulation within the PI3K pathway allows for extensive adaptation to external perturbation, both through rapid phosphorylation of key proteins as well as delayed transcriptional responses 1 . Transcriptional changes may also be accompanied by changes to the signaling code through epigenetic modifications 125 , thereby enabling adaptive resistance to spread across an entire cell population during subsequent division. Similarly, existing cells may acquire genetic alterations that make them resistant to PI3K inhibition1. The selective expansion of a few resistant cells may eventually result in tumors exhibiting full-blown drug resistance. Predicting drug-induced rewiring remains a challenge, however, with network analyses suggesting extensive plasticity 
1 and heterogeneity in the signaling response of cancer cells that have become resistant to PI3K

2 pathway inhibition 126 . These findings underscore the importance of systematic analyses of the

\section{Integration of drug therapy approaches with systems biology}

The pattern of limited therapeutic success is not unique to cancers with PI3K pathway activation. Dynamic mechanisms of adaptation operate within most if not all signaling pathways and, as demonstrated for the PI3K pathway, often extend beyond individual cells to encompass tissue cross-talk. It is therefore unsurprising that the results of traditional reductionist approaches have insufficient predictive power when it comes to therapeutic success - such methods are simply unable to capture the complexity of the system under study. The incorporation of knowledge about the PI3K code into rational therapeutic design may benefit from input from the rapidly maturing field of systems biology which is aimed at dealing with higher-order complexity. Briefly, systems biology approaches rely on dynamic, highcontent datasets and mathematical abstractions in the form of computational models. The best models are able to capture causal signaling relationships and can simulate their dynamics in response to various perturbations, be it pharmacological targeting or a mutation in a key component. The quality of such models is itself dependent on information from conventional studies, including the biochemical properties of individual signaling components, their temporal behavior and spatial organization 11.

A system can take many forms - an individual cell, homogenous cell populations, heterogenous tissues in vivo or entire organisms. More complex systems can be addressed with so-called multiscale modeling approaches11,127. Multiscale models of different tumors are emerging, taking into account nutrient diffusion rates, blood vessel density and individual probabilities for cell division, migration and death127. Similar models could be developed to 
integrate knowledge about the context-dependent PI3K signaling code in cell culture systems with the higher-order complexity of (patho)physiological systems in vivo.

\section{Optimising drug dose, drug combinations and temporal delivery}

The rationale for using mathematical models of signaling dynamics for improved therapeutic targeting, particularly in cancer, has been covered extensively11,13,122,128. Here, we will use examples from diseases of PI3K activation to illustrate more specifically how a quantative understanding of the context-specific PI3K code may benefit clinical drug development in this area.

Quantitative models of the relationship between PI3K signaling thresholds and contextspecific phenotypes could be used to determine the level of pathway inhibition that is needed to achieve suppression of a specific disease phenotype. In particular, simulations may predict that lower and potentially less toxic PI3K inhibitor doses are clinically effective, thereby offering a broader therapeutic window. For example, continuous inhibition of PI3K $\alpha$ with lowdose BYL719 (alpelisib, Novartis) is therapeutically beneficial for PROS patients, with no or minimal adverse effects8. This contrasts with high-dose PI3K inhibition to treat cancer, which, as mentioned above, is associated with glucose-mediated metabolic feedback and hyperinsulinemia124.

The remarkable effect of low-dose BYL719 in PROS begs the question whether the same therapeutic strategy should be tested in cancer129. Such low-dose PI3K pathway inhibition would not necessarily reduce excess cancer growth or proliferation because these phenomena are not driven only by PI3K, but could potentially allow for 'normalization' of PI3K signaling and thereby dampen ongoing tumour evolution79,130. It is tempting to speculate that one may even consider a low-dose cocktail of targeted drugs to simultaneously dampen multiple oncogenic pathways 130 . 
1 It is plausible that dynamic computational models of the PI3K code will not support a

2 beneficial effect of low-dose PI3K $\alpha$ inhibition in some or all tumour contexts. In such cases,

3 in silico experiments can be performed to identify alternative strategies, including intermittent

4 high-dose PI3K inhibition. Computational simulations may also identify critical protein-

5 protein interactions responsible for specificity in dynamic signal encoding. Rather than

6 inhibiting the oncogenic PI3K enzyme directly, modulation of such interactions will serve to

7 dampen some aspects of pathway activation but not others. The potential promise of this

8 strategy has also been discussed in the context of therapeutic targeting of the RAS/ERK

9 pathway, where blockade with an allosteric SHP2-targeting drug would limit the signaling flux

10 to the downstream oncogenic proteins 24.

11 Finally, quantitative tumor models that capture the PI3K code in various healthy and PI3K

mutant cells could provide insight into the interaction between tumor cells and their stroma,

and how this interaction may be modulated by therapeutic targeting. For example, PI3K $\delta$ -

targeting inhibitors, clinically approved for specific B-cell malignancies, act not only on the cancer cells themselves, but also disrupt the tumor cell-stroma interactions, a major aspect of their therapeutic effect131. Conversely, systemic high-dose PI3K $\delta$ inhibition also leads to adverse effects, inducing elements of immune activation as well as immunosuppression 132-134, once again highlighting the importance of getting PI3K signaling dynamics "just right".

Computational pan-cancer modeling has already demonstrated that the same oncogenic PIK3CA mutations are associated with context-specific regulatory programs and signaling networks in different cancers135, highlighting ways in which such knowledge can be used in the development of improved therapies. Thus, although the context-specific code of PI3K signaling presents a challenge for optimal therapeutic targeting, its quantitative understanding and incorporation into mathematical models may allow rational improvements of current and future clinical strategies. 
1 Once computational models of the context-dependent PI3K code become widely

2 available, subsequent in silico testing of dynamic drug dosing regimens comes at a relatively

3 low cost and has the power to test multiple conditions within a short amount of time. This

4 contrasts with current trials of dynamic dosing of PI3K inhibitors in cancer136-140, which are

5 limited to a handful of regimens and may lack sufficient pre-clinical evidence to determine the 6 optimal dosing pattern for in vivo application.

7

\section{SUMMARY AND FUTURE DIRECTIONS}

The first study providing experimental evidence for cellular encoding and decoding based on distinct PI3K signaling waves was published in 1999 (Ref.43). Two decades later, our understanding of the underlying PI3K signaling code and how it changes in different contexts. Thus, although we have a detailed understanding of the pathway's hardware, we know little about the controlling software and how it is programmed.

With this Review, we aimed to highlight the need for a better understanding of PI3K signaling, particularly how stimulus dynamics integrate with cell type, developmental stage, microenvironment and mutational status to provide distinct biological outputs (Fig. 6). It is clear that these parameters are poorly captured by the conventional studies of the pathway performed to date. Beyond its fundamental value, understanding dynamic PI3K signaling could also provide a framework to rationalize drug targeting approaches in cancer, such as intermittent dosing with high doses of PI3K inhibitor or continuous exposure to low-drug doses. Fundamentally, the key questions outlined in this review are generalizable and equally important to address in the context of most if not all other cell signaling pathways.

Tackling context-dependent PI3K signaling dynamics will be challenging, but continued technological advances and cross-disciplinary collaborations between biologists and computational scientists, should allow studies to connect the well-known PI3K signaling 
1 hardware with its underlying software, a task that is likely to shape the fourth decade of 2 research into this fascinating and druggable biological pathway. 
2 1. Fruman, D. A., Chiu, H., Hopkins, B. D., Bagrodia, S., Cantley, L. C. \& Abraham, R. T. The PI3K Pathway in Human Disease. Cell 170, 605-635 (2017).

2. Whitman, M., Downes, C. P., Keeler, M., Keller, T. \& Cantley, L. Type I phosphatidylinositol kinase makes a novel inositol phospholipid, phosphatidylinositol3-phosphate. Nature 332, 644-646 (1988).

7 3. Vanhaesebroeck, B., Stephens, L. \& Hawkins, P. PI3K signalling: the path to discovery and understanding. Nat. Rev. Mol. Cell Biol. 13, 195-203 (2012).

4. Bilanges, B., Posor, Y. \& Vanhaesebroeck, B. PI3K isoforms in cell signalling and vesicle trafficking. Nat. Rev. Mol. Cell Biol. 20, 515-534 (2019).

5. Vanhaesebroeck, B., Ali, K., Bilancio, A., Geering, B. \& Foukas, L. C. Signalling by PI3K isoforms: Insights from gene-targeted mice. Trends Biochem. Sci. 30, 194-204 (2005).

6. Kandoth, C., McLellan, M. D., Vandin, F., Ye, K., Niu, B. \& Lu, C. Mutational landscape and significance across 12 major cancer types. Nature 503, 333-339 (2013).

7. Lawrence, M. S., Stojanov, P., Mermel, C. H., Robinson, J. T., Garraway, L. A., overgrowth syndrome. Nature 558, 540-546 (2018).

9. Rao, V. K., Webster, S., Dalm, V. A. S. H., Šedivá, A., Van Hagen, P. M., Holland, S., 
Doucet, J., Guerini, D., Kalis, C., et al. Effective "activated PI3K $\delta$ syndrome”targeted therapy with the PI3K $\delta$ inhibitor leniolisib. Blood 130, 2307-2316 (2017).

10. Kholodenko, B. N. Cell-signalling dynamics in time and space. Nat. Rev. Mol. Cell Biol. 7, 165-176 (2006).

11. Kolch, W., Halasz, M., Granovskaya, M. \& Kholodenko, B. N. The dynamic control of signal transduction networks in cancer cells. Nat. Rev. Cancer 15, 515-527 (2015).

12. Bray, D. Protein molecules as computational elements in living cells. Nature 376, 307$312(1995)$. 
Drosophila Embryo. Dev. Cell 48, 361-370.e3 (2019).

21. de la Cova, C., Townley, R., Regot, S. \& Greenwald, I. A Real-Time Biosensor for ERK Activity Reveals Signaling Dynamics during C. elegans Cell Fate Specification. Dev. Cell 42, 542-553.e4 (2017).

22. Bugaj, L. J., Sabnis, A. J., Mitchell, A., Garbarino, J. E., Toettcher, J. E., Bivona, T. G. \& Lim, W. A. Cancer mutations and targeted drugs can disrupt dynamic signal encoding by the Ras-Erk pathway. Science. 361, eaao3048 (2018).

23. Kolch, W. \& Kiel, C. From oncogenic mutation to dynamic code. Science. 361, 844845 (2018).

24. Bivona, T. G. Dampening oncogenic RAS signaling. Science. 363, 1280-1281 (2019).

25. Lahav, G., Rosenfeld, N., Sigal, A., Geva-Zatorsky, N., Levine, A. J., Elowitz, M. B. \& Alon, U. Dynamics of the p53-Mdm2 feedback loop in individual cells. Nat. Genet. 36, 147-150 (2004).

26. Tay, S., Hughey, J. J., Lee, T. K., Lipniacki, T., Quake, S. R. \& Covert, M. W. Singlecell NF-B dynamics reveal digital activation and analogue information processing. Nature 466, 267-271 (2010).

27. DeFelice, M. M., Clark, H. R., Hughey, J. J., Maayan, I., Kudo, T., Gutschow, M. V., Covert, M. W. \& Regot, S. NF-кB signaling dynamics is controlled by a dose-sensing autoregulatory loop. Sci. Signal. 12, eaau3568 (2019).

28. Noren, D. P., Chou, W. H., Lee, S. H., Qutub, A. A., Warmflash, A., Wagner, D. S., Popel, A. S. \& Levchenko, A. Endothelial cells decode VEGF-mediated Ca2+ signaling patterns to produce distinct functional responses. Sci. Signal. 9, 1-13 (2016).

29. Yissachar, N., Sharar Fischler, T., Cohen, A. A., Reich-Zeliger, S., Russ, D., Shifrut, E., Porat, Z. \& Friedman, N. Dynamic Response Diversity of NFAT Isoforms in Individual Living Cells. Mol. Cell 49, 322-330 (2013). 
1 30. Sako, K., Pradhan, S. J., Barone, V., Inglés-Prieto, Á., Müller, P., Ruprecht, V., Čapek,

D., Galande, S., Janovjak, H. \& Heisenberg, C. P. Optogenetic Control of Nodal Signaling Reveals a Temporal Pattern of Nodal Signaling Regulating Cell Fate Specification during Gastrulation. Cell Rep. 16, 866-877 (2016).

31. Heemskerk, I., Burt, K., Miller, M., Chhabra, S., Guerra, M. C., Liu, L. \& Warmflash, A. Rapid changes in morphogen concentration control self-organized patterning in human embryonic stem cells. Elife 8, 1-28 (2019).

32. Sorre, B., Warmflash, A., Brivanlou, A. H. \& Siggia, E. D. Encoding of temporal signals by the TGF- $\beta$ Pathway and implications for embryonic patterning. Dev. Cell 30, 334-342 (2014).

33. Warmflash, A., Zhang, Q., Sorre, B., Vonica, A., Siggia, E. D. \& Brivanlou, A. H. Dynamics of TGF- signaling reveal adaptive and pulsatile behaviors reflected in the nuclear localization of transcription factor Smad4. Proc. Natl. Acad. Sci. 109, E1947E1956 (2012).

34. Massey, J., Liu, Y., Alvarenga, O., Saez, T., Schmerer, M. \& Warmflash, A. Synergy with TGF $\beta$ ligands switches WNT pathway dynamics from transient to sustained during human pluripotent cell differentiation. Proc. Natl. Acad. Sci. U. S. A. 116, 4989-4998 (2019).

35. Dessaud, E., Yang, L. L., Hill, K., Cox, B., Ulloa, F., Ribeiro, A., Mynett, A., Novitch, B. G. \& Briscoe, J. Interpretation of the sonic hedgehog morphogen gradient by a temporal adaptation mechanism. Nature 450, 717-720 (2007).

36. Balaskas, N., Ribeiro, A., Panovska, J., Dessaud, E., Sasai, N., Page, K. M., Briscoe, J. \& Ribes, V. Gene regulatory logic for reading the sonic hedgehog signaling gradient in the vertebrate neural tube. Cell 148, 273-284 (2012).

37. Lee, C., Shin, H. \& Kimble, J. Dynamics of Notch-Dependent Transcriptional Bursting 
in Its Native Context. Dev. Cell 50, 426-435.e4 (2019).

38. Nandagopal, N., Santat, L. A., LeBon, L., Sprinzak, D., Bronner, M. E. \& Elowitz, M. B. Dynamic Ligand Discrimination in the Notch Signaling Pathway. Cell 172, 869880.e19 (2018).

39. Falo-Sanjuan, J., Lammers, N. C., Garcia, H. G. \& Bray, S. J. Enhancer Priming Enables Fast and Sustained Transcriptional Responses to Notch Signaling. Dev. Cell 50, 411-425.e8 (2019).

40. Kubota, H., Noguchi, R., Toyoshima, Y., Ozaki, Y. I., Uda, S., Watanabe, K., Ogawa, W. \& Kuroda, S. Temporal Coding of Insulin Action through Multiplexing of the AKT Pathway. Mol. Cell 46, 820-832 (2012).

41. Tan, S. X., Ng, Y., Meoli, C. C., Kumar, A., Khoo, P. S., Fazakerley, D. J., Junutula, J. R., Vali, S., James, D. E. \& Stöckli, J. Amplification and demultiplexing in insulinregulated Akt protein kinase pathway in adipocytes. J. Biol. Chem. 287, 6128-6138 (2012).

42. Madsen, R. R., Vanhaesebroeck, B. \& Semple, R. K. Cancer-Associated PIK3CA Mutations in Overgrowth Disorders. Trends Mol. Med. 24, 856-870 (2018).

43. Jones, S. M., Klinghoffer, R., Prestwich, G. D., Toker, A. \& Kazlauskas, A. PDGF induces an early and a late wave of PI 3-kinase activity, and only the late wave is required for progression through G1. Curr. Biol. 9, 512-521 (1999).

44. Tengholm, A. \& Meyer, T. A PI3-Kinase signaling code for insulin-triggered insertion of glucose transporters into the plasma membrane. Curr. Biol. 12, 1871-1876 (2002).

45. Wiese, R. J., Mastick, C. C., Lazar, D. F. \& Saltiel, A. R. Activation of mitogenactivated protein kinase and phosphatidylinositol 3'-kinase is not sufficient for the hormonal stimulation of glucose uptake, lipogenesis, or glycogen synthesis in 3T3-L1 adipocytes. Journal of Biological Chemistry 270, 3442-3446 (1995). 
46. Sedaghat, A. R., Sherman, A. \& Quon, M. J. A mathematical model of metabolic insulin signaling pathways. Am. J. Physiol. Endocrinol. Metab. 283, E1084-E1101 (2002).

47. Sulaimanov, N., Klose, M., Busch, H. \& Boerries, M. Understanding the mTOR signaling pathway via mathematical modeling. Wiley Interdiscip. Rev. Syst. Biol. Med. 9, 1-18 (2017).

48. Naguib, A. Following the trail of lipids: Signals initiated by PI3K function at multiple cellular membranes. Sci. Signal. 9, re4 (2016).

49. Gray, C. W. \& Coster, A. C. F. The Akt switch model: Is location sufficient? J. Theor. Biol. 398, 103-11 (2016).

50. Klippel, A., Escobedo, M., Wachowicz, M. S., Apell, G., Brown, T. W., Giedlin, M., Kavanaugh, W. M. \& Williams, L. T. Activation of phosphatidylinositol 3-kinase is sufficient for cell cycle entry and promotes cellular changes characteristic of oncogenic transformation. Mol. Cell. Biol. 18, 5699-5711 (1998).

51. Alvarez, B., Martínez-A., C., Burgering, B. M. T. \& Carrera, A. C. Forkhead transcription factors contribute to execution of the mitotic programme in mammals. Nature 413, 744-747 (2001).

52. Marques, M., Kumar, A., Cortes, I., Gonzalez-Garcia, A., Hernandez, C., MorenoOrtiz, M. C. \& Carrera, A. C. Phosphoinositide 3-Kinases p110 and p110 Regulate Cell Cycle Entry, Exhibiting Distinct Activation Kinetics in G1 Phase. Mol. Cell. Biol. 28, 2803-2814 (2008).

53. Maddika, S., Ande, S. R., Wiechec, E., Hansen, L. L., Wesselborg, S. \& Los, M. Aktmediated phosphorylation of CDK2 regulates its dual role in cell cycle progression and apoptosis. J. Cell Sci. 121, 979-988 (2008).

54. Roberts, E. C., Shapiro, P. S., Nahreini, T. S., Pages, G., Pouyssegur, J. \& Ahn, N. G. 
Distinct cell cycle timing requirements for extracellular signal-regulated kinase and phosphoinositide 3-kinase signaling pathways in somatic cell mitosis. Mol. Cell. Biol. 22, 7226-41 (2002).

55. Shtivelman, E., Sussman, J. \& Stokoe, D. A role for PI 3-kinase and PKB activity in the G2/M phase of the cell cycle. Curr. Biol. 12, 919-924 (2002).

56. Tonic, I., Yu, W. N., Park, Y., Chen, C. C. \& Hay, N. Akt activation emulates Chk1 inhibition and Bcl2 overexpression and abrogates $\mathrm{G} 2$ cell cycle checkpoint by inhibiting BRCA1 foci. J. Biol. Chem. 285, 23790-23798 (2010).

57. Fujita, K., Toyoshima, Y., Uda, S., Ozaki, Y., Kubota, H. \& Kuroda, S. Decoupling of Receptor and Downstream Signals in the Akt Pathway by Its Low-Pass Filter Characteristics. Sci. Signal. 3, ra56-ra56 (2010).

58. Poerksen, N., Hollingdal, M., Juhl, C., Butler, P., Veldhuis, J. D. \& Schmitz, O. Pulsatile insulin secretion: Detection, regulation, and role in diabetes. in Diabetes 51, $245-254$ (2002).

59. Polonsky, K. S., Given, B. D., Van Cauter, E., Hirsch, L., Shapiro, E. T., Tillil, H., Beebe, C., Galloway, J., Frank, B. H. \& Karrison, T. Twenty-four-hour profiles and pulsatile patterns of insulin secretion in normal and obese subjects. Quantitative study of insulin secretion and clearance in normal and obese subjects. J. Clin. Invest. 81, $442-448(1988)$.

60. Kubota, H., Uda, S., Matsuzaki, F., Yamauchi, Y. \& Kuroda, S. In Vivo Decoding Mechanisms of the Temporal Patterns of Blood Insulin by the Insulin-AKT Pathway in the Liver. Cell Syst. 7, 118-128.e3 (2018).

61. Okkenhaug, K. Rules of engagement: Distinct functions for the four class I PI3K catalytic isoforms in immunity. Ann. N. Y. Acad. Sci. 1280, 24-26 (2013).

62. Shojaee, S., Chan, L. N., Buchner, M., Cazzaniga, V., Cosgun, K. N., Geng, H., Qiu, 
Y. H., von Minden, M. D., Ernst, T., Hochhaus, A., Cazzaniga, G., Melnick, A., Kornblau, S. M., Graeber, T. G., Wu, H., et al. PTEN opposes negative selection and enables oncogenic transformation of pre-B cells. Nat. Med. 22, 379-387 (2016).

63. Chen, J. Y., Lin, J. R., Cimprich, K. A. \& Meyer, T. A Two-Dimensional ERK-AKT Signaling Code for an NGF-Triggered Cell-Fate Decision. Mol. Cell 45, 196-209 (2012).

64. Sampattavanich, S., Steiert, B., Kramer, B. A., Gyori, B. M., Albeck, J. G. \& Sorger, P. K. Encoding Growth Factor Identity in the Temporal Dynamics of FOXO3 under the Combinatorial Control of ERK and AKT Kinases. Cell Syst. 6, 664-678.e9 (2018).

65. Liu, S.-L., Wang, Z.-G., Hu, Y., Xin, Y., Singaram, I., Gorai, S., Zhou, X., Shim, Y., Min, J.-H., Gong, L.-W., Hay, N., Zhang, J. \& Cho, W. Quantitative Lipid Imaging Reveals a New Signaling Function of Phosphatidylinositol-3,4-Bisphophate: Isoformand Site-Specific Activation of Akt. Mol. Cell 71, 1092-1104.e5 (2018).

66. Wills, R. C., Goulden, B. D. \& Hammond, G. R. V. Genetically encoded lipid biosensors. Mol. Biol. Cell 29, 1526-1532 (2018).

67. Ozaki, Y. I., Uda, S., Saito, T. H., Chung, J., Kubota, H. \& Kuroda, S. A quantitative image cytometry technique for time series or population analyses of signaling networks. PLoS One 5, (2010).

68. Lin, J., Fallahi-Sichani, M. \& Sorger, P. K. Highly multiplexed imaging of single cells using a high-throughput cyclic immunofluorescence method. Nat. Commun. 6, 8390 (2015).

69. Gut, G., Herrmann, M. D. \& Pelkmans, L. Multiplexed protein maps link subcellular organization to cellular states. Science. 361, (2018).

70. Gerosa, L., Chidley, C., Froehlich, F., Sanchez, G., Lim, S. K., Muhlich, J., Chen, J.Y., Baker, G., Schapiro, D., Shi, T., Yi, Li., Nicora, C. D., Claas, A., Lauffenburger, 
D. A., Qian, W.-J., et al. Sporadic ERK pulses drive non-genetic resistance in drugadapted BRAF. bioRxiv (preprint) 1-44 (2019). doi:10.1101/762294

71. Petersen, M. C. \& Shulman, G. I. Mechanisms of Insulin Action and Insulin Resistance. Physiol. Rev. 98, 2133-2223 (2018).

72. Rangarajan, A., Hong, S. J., Gifford, A. \& Weinberg, R. A. Species- and cell typespecific requirements for cellular transformation. Cancer Cell 6, 171-183 (2004).

73. Boehm, J. S., Hession, M. T., Bulmer, S. E. \& Hahn, W. C. Transformation of Human and Murine Fibroblasts without Viral Oncoproteins. Mol. Cell. Biol. 25, 6464-6474 (2005).

74. Astle, M. V, Hannan, K. M., Ng, P. Y., Lee, R. S., George, J., Hsu, K., Haupt, Y., Hannan, R. D. \& Pearson, R. B. AKT induces senescence in human cells via mTORC1 and p53 in the absence of DNA damage: implications for targeting mTOR during malignancy. Oncogene 31, 1949-1962 (2012).

75. Chen, Z., Trotman, L. C., Shaffer, D., Lin, H.-K., Dotan, Z. A., Niki, M., Koutcher, J. A., Scher, H. I., Ludwig, T., Gerald, W., Cordon-Cardo, C. \& Pandolfi, P. P. Crucial role of p53-dependent cellular senescence in suppression of Pten-deficient tumorigenesis. Nature 436, 725-730 (2005).

76. Kim, J.-S., Lee, C., Bonifant, C. L., Ressom, H. \& Waldman, T. Activation of p53dependent growth suppression in human cells by mutations in PTEN or PIK3CA. Mol. Cell. Biol. 27, 662-77 (2007).

77. Miyauchi, H., Minamino, T., Tateno, K., Kunieda, T., Toko, H. \& Komuro, I. Akt negatively regulates the in vitro lifespan of human endothelial cells via a p53/p21dependent pathway. EMBO J. 23, 212-20 (2004).

78. Yuan, T. L., Wulf, G., Burga, L. \& Cantley, L. C. Cell-to-cell variability in PI3K protein level regulates PI3K-AKT pathway activity in cell populations. Curr. Biol. 21, 
173-183 (2011).

79. Berenjeno, I. M., Piñeiro, R., Castillo, S. D., Pearce, W., McGranahan, N., Dewhurst, S. M., Meniel, V., Birkbak, N. J., Lau, E., Sansregret, L., Morelli, D., Kanu, N., Srinivas, S., Graupera, M., Parker, V. E. R., et al. Oncogenic PIK3CA induces centrosome amplification and tolerance to genome doubling. Nat. Commun. 8, 1773 (2017).

80. Ying, Z., Sandoval, M. \& Beronja, S. Oncogenic activation of PI3K induces progenitor cell differentiation to suppress epidermal growth. Nat. Cell Biol. 20, 1 (2018).

81. Kennedy, A. L., Morton, J. P., Manoharan, I., Nelson, D. M., Jamieson, N. B., Pawlikowski, J. S., McBryan, T., Doyle, B., McKay, C., Oien, K. A., Enders, G. H., Zhang, R., Sansom, O. J. \& Adams, P. D. Activation of the PIK3CA/AKT Pathway Suppresses Senescence Induced by an Activated RAS Oncogene to Promote Tumorigenesis. Mol. Cell 42, 36-49 (2011).

82. Zhang, J., Grindley, J. C., Yin, T., Jayasinghe, S., He, X. C., Ross, J. T., Haug, J. S., Rupp, D., Porter-Westpfahl, K. S., Wiedemann, L. M., Wu, H. \& Li, L. PTEN maintains haematopoietic stem cells and acts in lineage choice and leukaemia prevention. Nature 441, 518-522 (2006).

83. Yilmaz, Ö. H., Valdez, R., Theisen, B. K., Guo, W., Ferguson, D. O., Wu, H. \& Morrison, S. J. Pten dependence distinguishes haematopoietic stem cells from leukaemia-initiating cells. Nature 441, 475-482 (2006).

84. Wang, G., Zhu, H., Situ, C., Han, L., Yu, Y., Cheung, T. H., Liu, K. \& Wu, Z. p110 of PI3K is necessary and sufficient for quiescence exit in adult muscle satellite cells. EMBO J. 37, e98239 (2018).

85. Ling, L. S., Voskas, D. \& Woodgett, J. R. Activation of PDK-1 maintains mouse embryonic stem cell self-renewal in a PKB-dependent manner. Oncogene 32, 5397- 
5408 (2013).

86. Watanabe, S., Umehara, H., Murayama, K., Okabe, M., Kimura, T. \& Nakano, T. Activation of Akt signaling is sufficient to maintain pluripotency in mouse and primate embryonic stem cells. Oncogene 25, 2697-2707 (2006).

87. Di Cristofano, A., Pesce, B., Cordon-Cardo, C. \& Pandolfi, P. P. Pten is essential for embryonic development and tumour suppression. Nat. Genet. 19, 348-355 (1998).

88. Alva, J. A., Lee, G. E., Escobar, E. E. \& Pyle, A. D. Phosphatase and Tensin Homolog Regulates the Pluripotent State and Lineage Fate Choice in Human Embryonic Stem Cells. Stem Cells 29, 1952-1962 (2011).

89. Madsen, R. R., Knox, R. G., Pearce, W., Lopez, S., Mahler-Araujo, B., McGranahan, N., Vanhaesebroeck, B. \& Semple, R. K. Oncogenic PIK3CA promotes cellular stemness in an allele dose-dependent manner. Proc. Natl. Acad. Sci. 116, 8380-8389 (2019).

90. Koren, S., Reavie, L., Couto, J. P., De Silva, D., Stadler, M. B., Roloff, T., Britschgi, A., Eichlisberger, T., Kohler, H., Aina, O., Cardiff, R. D. \& Bentires-Alj, M. PIK3CA(H1047R) induces multipotency and multi-lineage mammary tumours. Nature 525, 114-8 (2015).

91. Van Keymeulen, A., Lee, M. Y., Ousset, M., Brohée, S., Rorive, S., Giraddi, R. R., Wuidart, A., Bouvencourt, G., Dubois, C., Salmon, I., Sotiriou, C., Phillips, W. a. \& Blanpain, C. Reactivation of multipotency by oncogenic PIK3CA induces breast tumour heterogeneity. Nature 525, 119-23 (2015).

92. Madsen, R. R., Longden, J., Knox, R. G., Xavier, R., Völlmy, F., Macleod, K. G., Moniz, L., Carragher, N. O., McGranahan, N., Linding, R., Vanhaesebroeck, B. \& Semple, R. K. High-dose oncogenic PIK3CA drives constitutive cellular stemness through self-sustained TGF $\beta$ pathway activation. bioRxiv (preprint) (2019). 
doi:10.1101/753830

93. Monk, M. \& Holding, C. Human embryonic genes re-expressed in cancer cells. Oncogene 20, 8085-8091 (2001).

94. Yan, X., Himburg, H. A., Pohl, K., Quarmyne, M., Tran, E., Zhang, Y., Fang, T., Kan, J., Chao, N. J., Zhao, L., Doan, P. L. \& Chute, J. P. Deletion of the Imprinted Gene Grb10 Promotes Hematopoietic Stem Cell Self-Renewal and Regeneration. Cell Rep. 17, 1584-1594 (2016).

95. Rivera-Gonzalez, G. C., Shook, B. A., Andrae, J., Holtrup, B., Bollag, K., Betsholtz, C., Rodeheffer, M. S. \& Horsley, V. Skin Adipocyte Stem Cell Self-Renewal Is Regulated by a PDGFA/AKT-Signaling Axis. Cell Stem Cell 19, 738-751 (2016).

96. Kobayashi, H., Butler, J. M., O’Donnell, R., Kobayashi, M., Ding, B.-S., Bonner, B., Chiu, V. K., Nolan, D. J., Shido, K., Benjamin, L. \& Rafii, S. Angiocrine factors from Akt-activated endothelial cells balance self-renewal and differentiation of haematopoietic stem cells. Nat. Cell Biol. 12, 1046-1056 (2010).

97. Eves, E. M., Xiong, W., Bellacosa, A., Kennedy, S. G., Tsichlis, P. N., Rosner, M. R. \& Hay, N. Akt, a Target of Phosphatidylinositol 3-Kinase, Inhibits Apoptosis in a Differentiating Neuronal Cell Line. Mol. Cell. Biol. 18, 2143-2152 (1998).

98. Ahmed, N. N., Grimes, H. L., Bellacosa, A., Chan, T. O. \& Tsichlis, P. N. Transduction of interleukin-2 antiapoptotic and proliferative signals via Akt protein kinase. Proc. Natl. Acad. Sci. 94, 3627-3632 (2002).

99. Kennedy, S. G., Wagner, A. J., Conzen, S. D., Jordán, J., Bellacosa, A., Tsichlis, P. N. \& Hay, N. The PI 3-kinase/Akt signaling pathway delivers an anti-apoptotic signal. Genes Dev. 11, 701-713 (1997).

100. Philpott, K. L., McCarthy, M. J., Klippel, A. \& Rubin, L. L. Activated phosphatidylinositol 3-kinase and Akt kinase promote survival of superior cervical 
neurons. J. Cell Biol. 139, 809-815 (1997).

101. Yao, R. \& Cooper, G. M. Requirement for phosphatidylinositol-3 kinase in the prevention of apoptosis by nerve growth factor. Science. 267, 2003-2006 (1995).

102. Kulik, G., Klippel, A. \& Weber, M. J. Antiapoptotic signalling by the insulin-like growth factor I receptor, phosphatidylinositol 3-kinase, and Akt. Mol. Cell. Biol. 17, 1595-1606 (1997).

103. Khwaja, A., Rodriguez-Viciana, P., Wennström, S., Warne, P. H. \& Downward, J. Matrix adhesion and Ras transformation both activate a phosphoinositide 3-OH kinase and protein kinase B/Akt cellular survival pathway. EMBO J. 16, 2783-2793 (1997).

104. Mirza, A. M., Kohn, A. D., Roth, R. A. \& McMahon, M. Oncogenic transformation of cells by a conditionally active form of the protein kinase Akt/PKB. Cell Growth Differ. 11, 279-92 (2000).

105. Robey, R. B. \& Hay, N. Is Akt the 'Warburg kinase'?-Akt-energy metabolism interactions and oncogenesis. Semin. Cancer Biol. 19, 25-31 (2009).

106. Aki, T., Yamaguchi, K., Fujimiya, T. \& Mizukami, Y. Phosphoinositide 3-kinase accelerates autophagic cell death during glucose deprivation in the rat cardiomyocytederived cell line H9c2. Oncogene 22, 8529-8535 (2003).

107. Fan, Y., Dickman, K. G. \& Zong, W. X. Akt and c-Myc differentially activate cellular metabolic programs and prime cells to bioenergetic inhibition. J. Biol. Chem. 285, 7324-7333 (2010).

108. Aki, T., Mizukami, Y., Oka, Y., Yamaguchi, K., Uemura, K., Fujimiya, T. \& Yoshida, K. Phosphoinositide 3-kinase accelerates necrotic cell death during hypoxia. Biochem. J. 358, 481-487 (2001).

109. Hamanaka, Y., Mukai, M., Shimamura, M., Kitagawa, T., Nishida, T., Isohashi, F., Ito, T., Nishizawa, Y., Tatsuta, M., Matsuda, H. \& Inoue, M. Suppression of PI3K/mTOR 
pathway rescues LLC cells from cell death induced by hypoxia. Biochem. Biophys. Res. Commun. 330, 318-326 (2005).

110. Shack, S., Wang, X., Kokkonen, G. \& M. Caveolin-induced activation of the phosphatidylinositol 3-kinase/Akt pathway increases arsenite cytotoxicity. Mol. Cell. Biol. 23, 2407-2414 (2003).

111. Van Gorp, A. G. M., Pomeranz, K. M., Birkenkamp, K. U., Hui, R. C. Y., Lam, E. W. F. \& Coffer, P. J. Chronic Protein Kinase B (PKB/c-akt) activation leads to apoptosis induced by oxidative stress-mediated Foxo3a transcriptional up-regulation. Cancer Res. 66, 10760-10769 (2006).

112. Endo, H., Murata, K., Mukai, M., Ishikawa, O. \& Inoue, M. Activation of Insulin-like Growth Factor Signaling Induces Apoptotic Cell Death Under Prolonged Hypoxia by Enhancing Endoplasmic Reticulum Stress Response. Cancer Res. 67, 8095-8103 (2007).

113. Nimbalkar, D., Henry, M. K. \& Quelle, F. W. Cytokine activation of phosphoinositide 3-kinase sensitizes hematopoietic cells to cisplatin-induced death. Cancer Res. 63, 1034-1039 (2003).

114. Liu, Q., Qiu, J., Liang, M., Golinski, J., Van Leyen, K., Jung, J. E., You, Z., Lo, E. H., Degterev, A. \& Whalen, M. J. Akt and mTOR mediate programmed necrosis in neurons. Cell Death Dis. 5, 1-10 (2014).

115. Lu, B., Wang, L., Stehlik, C., Medan, D., Huang, C., Hu, S., Chen, F., Shi, X. \& Rojanasakul, Y. Phosphatidylinositol 3-Kinase/Akt Positively Regulates Fas (CD95)Mediated Apoptosis in Epidermal Cl41 Cells. J. Immunol. 176, 6785-6793 (2006).

116. Stallaert, W., Brüggemann, Y., Sabet, O., Baak, L., Gattiglio, M. \& Bastiaens, P. I. H. Contact inhibitory Eph signaling suppresses EGF-promoted cell migration by decoupling EGFR activity from vesicular recycling. Sci. Signal. 11, (2018). 
1 117. Meyer, R., D’Alessandro, L. A., Kar, S., Kramer, B., She, B., Kaschek, D., Hahn, B., Wrangborg, D., Karlsson, J., Kvarnström, M., Jirstrand, M., Lehmann, W. D., Timmer, J., Höfer, T. \& Klingmüller, U. Heterogeneous kinetics of AKT signaling in individual cells are accounted for by variable protein concentration. Front. Physiol. 3 NOV, 1-14 (2012).

118. Sigal, A., Milo, R., Cohen, A., Geva-Zatorsky, N., Klein, Y., Liron, Y., Rosenfeld, N., Danon, T., Perzov, N. \& Alon, U. Variability and memory of protein levels in human cells. Nature 444, 643-646 (2006).

119. Creixell, P., Schoof, E. M., Simpson, C. D., Longden, J., Miller, C. J., Lou, H. J., Perryman, L., Cox, T. R., Zivanovic, N., Palmeri, A., Wesolowska-andersen, A., Helmer-citterich, M., Ferkinghoff-borg, J., Itamochi, H., Bodenmiller, B., et al. Kinome-wide Decoding of Network Attacking Mutations Driving Cancer Signaling. Cell 163, 202-217 (2015).

120. Dogruluk, T., Tsang, Y. H., Espitia, M., Chen, F., Chen, T., Chong, Z., Appadurai, V., Dogruluk, A., Eterovic, A. K., Bonnen, P. E., Creighton, C. J., Chen, K., Mills, G. B. \& Scott, K. L. Identification of Variant-Specific Functions of PIK3CA by Rapid Phenotyping of Rare Mutations. Cancer Res. 75, 5341-54 (2015).

121. Zhang, Y., Kwok-Shing Ng, P., Kucherlapati, M., Chen, F., Liu, Y., Tsang, Y. H., de Velasco, G., Jeong, K. J., Akbani, R., Hadjipanayis, A., Pantazi, A., Bristow, C. A., Lee, E., Mahadeshwar, H. S., Tang, J., et al. A Pan-Cancer Proteogenomic Atlas of PI3K/AKT/mTOR Pathway Alterations. Cancer Cell 31, 820-832.e3 (2017).

122. Wang, Z. \& Deisboeck, T. S. Dynamic Targeting in Cancer Treatment. Front. Physiol. 10, 1-9 (2019).

123. Janku, F., Yap, T. A. \& Meric-Bernstam, F. Targeting the PI3K pathway in cancer: are we making headway? Nat. Rev. Clin. Oncol. 15, 273-291 (2018). 
1 124. Hopkins, B. D., Pauli, C., Du, X., Wang, D. G., Li, X., Wu, D., Amadiume, S. C., Goncalves, M. D., Hodakoski, C., Lundquist, M. R., Bareja, R., Ma, Y., Harris, E. M., Sboner, A., Beltran, H., et al. Suppression of insulin feedback enhances the efficacy of PI3K inhibitors. Nature 560, 499-503 (2018).

125. Easwaran, H., Tsai, H. C. \& Baylin, S. B. Cancer Epigenetics: Tumor Heterogeneity, Plasticity of Stem-like States, and Drug Resistance. Mol. Cell 54, 716-727 (2014).

126. Wilkes, E. H., Terfve, C., Gribben, J. G., Saez-Rodriguez, J. \& Cutillas, P. R. Empirical inference of circuitry and plasticity in a kinase signaling network. Proc. Natl. Acad. Sci. U. S. A. 112, 7719-24 (2015).

127. Masoudi-Nejad, A., Bidkhori, G., Hosseini Ashtiani, S., Najafi, A., Bozorgmehr, J. H. \& Wang, E. Cancer systems biology and modeling: Microscopic scale and multiscale approaches. Semin. Cancer Biol. 30, 60-69 (2015).

128. Saez-Rodriguez, J., MacNamara, A. \& Cook, S. Modeling Signaling Networks to Advance New Cancer Therapies. Annu. Rev. Biomed. Eng. 17, 143-163 (2015).

129. Semple, R. K. \& Vanhaesebroeck, B. Lessons for cancer drug treatment from tackling a non-cancerous overgrowth syndrome. Nature 558, 523-525 (2018).

130. Vanhaesebroeck, Bilanges, Madsen, Dale, Lau \& Vladimirou. Perspective: Potential Impact and Therapeutic Implications of Oncogenic PI3K Activation on Chromosomal Instability. Biomolecules 9, 331 (2019).

131. Okkenhaug, K., Graupera, M. \& Vanhaesebroeck, B. Targeting PI3K in cancer: Impact on tumor cells, their protective stroma, angiogenesis, and immunotherapy. Cancer Discov. 6, 1090-1105 (2016).

132. Ali, K., Soond, D. R., Piñeiro, R., Hagemann, T., Pearce, W., Lim, E. L., Bouabe, H., Scudamore, C. L., Hancox, T., Maecker, H., Friedman, L., Turner, M., Okkenhaug, K. \& Vanhaesebroeck, B. Inactivation of PI(3)K p1 $10 \delta$ breaks regulatory T-cell-mediated 
immune tolerance to cancer. Nature 510, 407-411 (2014).

133. Lampson, B. L., Kasar, S. N., Matos, T. R., Morgan, E. A., Rassenti, L., Davids, M. S., Fisher, D. C., Freedman, A. S., Jacobson, C. A., Armand, P., Abramson, J. S., Arnason, J. E., Kipps, T. J., Fein, J., Fernandes, S., et al. Idelalisib given front-line for treatment of chronic lymphocytic leukemia causes frequent immune-mediated hepatotoxicity. Blood 128, 195-203 (2016).

134. Chellappa, S., Kushekhar, K., Munthe, L. A., Tjønnfjord, G. E., Aandahl, E. M., Okkenhaug, K. \& Taskén, K. The PI3K p110 Isoform Inhibitor Idelalisib Preferentially Inhibits Human Regulatory T Cell Function. J. Immunol. 202, 13971405 (2019).

135. Osmanbeyoglu, H. U., Toska, E., Chan, C., Baselga, J. \& Leslie, C. S. Pancancer modelling predicts the context-specific impact of somatic mutations on transcriptional programs. Nat. Commun. 8, (2017).

136. Hoeflich, K. P., Merchant, M., Orr, C., Chan, J., Otter, D. Den, Berry, L., Kasman, I., Koeppen, H., Rice, K., Yang, N. Y., Engst, S., Johnston, S., Friedman, L. S. \& Belvin, M. Intermittent administration of MEK inhibitor GDC-0973 plus pi3k inhibitor GDC0941 triggers robust apoptosis and tumor growth inhibition. Cancer Res. 72, 210-219 (2012)

137. Will, M., Qin, A. C. R., Toy, W., Yao, Z., Rodrik-Outmezguine, V., Schneider, C., Huang, X., Monian, P., Jiang, X., De Stanchina, E., Baselga, J., Liu, N., Chandarlapaty, S. \& Rosen, N. Rapid induction of apoptosis by PI3K inhibitors is dependent upon their transient inhibition of RAS-ERK signaling. Cancer Discov. 4, 334-348 (2014).

138. Hudson, K., Hancox, U. J., Trigwell, C., McEwen, R., Polanska, U. M., Nikolaou, M., Morentin Gutierrez, P., Avivar-Valderas, A., Delpuech, O., Dudley, P., Hanson, L., 
Ellston, R., Jones, A., Cumberbatch, M., Cosulich, S. C., et al. Intermittent High-Dose Scheduling of AZD8835, a Novel Selective Inhibitor of PI3K $\alpha$ and PI3K $\delta$, Demonstrates Treatment Strategies for PIK3CA-Dependent Breast Cancers. Mol. Cancer Ther. 15, 877-89 (2016).

139. Toska, E. \& Baselga, J. Pharmacology in the era of targeted therapies: The case of PI3K inhibitors. Clin. Cancer Res. 22, 2099-2101 (2016).

140. Yang, W., Hosford, S. R., Dillon, L. M., Shee, K., Liu, S. C., Bean, J. R., Salphati, L., Pang, J., Zhang, X., Nannini, M. A., Demidenko, E., Bates, D., Lewis, L. D., Marotti, J. D., Eastman, A. R., et al. Strategically Timing Inhibition of Phosphatidylinositol 3Kinase to Maximize Therapeutic Index in Estrogen Receptor Alpha-Positive, PIK3CAMutant Breast Cancer. Clin. Cancer Res. 22, 2250-2260 (2016).

141. Feng, S., Laketa, V., Stein, F., Rutkowska, A., MacNamara, A., Depner, S., Klingmüller, U., Saez-Rodriguez, J. \& Schultz, C. A rapidly reversible chemical dimerizer system to study lipid signaling in living cells. Angew. Chemie - Int. Ed. 53, 6720-6723 (2014).

142. Toettcher, J. E., Gong, D., Lim, W. \& Weiner, O. D. Light-based feedback for controlling intracellular signaling dynamics. Nat. Methods 8, 837-839 (2011).

143. Tischer, D. \& Weiner, O. D. Illuminating cell signalling with optogenetic tools. Nat Rev Mol Cell Biol 15, 551-558 (2014).

144. Kawano, F., Suzuki, H., Furuya, A. \& Sato, M. Engineered pairs of distinct photoswitches for optogenetic control of cellular proteins. Nat. Commun. 6, 6256 (2015).

145. Brachmann, S. M., Ueki, K., Engelman, J. A., Kahn, R. C. \& Cantley, L. C. Phosphoinositide 3-kinase catalytic subunit deletion and regulatory subunit deletion have opposite effects on insulin sensitivity in mice. Mol. Cell. Biol. 25, 1596-607 
146. Gross, S. M. \& Rotwein, P. Mapping growth-factor-modulated Akt signaling dynamics. J. Cell Sci. 129, 2052-2063 (2016).

4 147. Gross, S. M. \& Rotwein, P. Unraveling Growth Factor Signaling and Cell Cycle Progression in Individual Fibroblasts. J. Biol. Chem. 291, 14628-14638 (2016).

148. Katsura, Y., Kubota, H., Kunida, K., Kanno, A., Kuroda, S. \& Ozawa, T. An optogenetic system for interrogating the temporal dynamics of Akt. Sci. Rep. 5, 14589 (2015)

149. Manning, B. D. \& Toker, A. AKT/PKB Signaling: Navigating the Network. Cell 169, $381-405$ (2017).

Acknowledgments: We are grateful to Robert Semple, Benoit Bilanges, Sarah Conduit, Luca Gerosa and James Longden for their helpful feedback during the preparation of this manuscript.

Funding: Work in the laboratory of B.V. is supported by PTEN Research, Cancer Research UK (C23338/A25722), the UK Biotechnology and Biological Sciences Research Council (BB/I007806/1, BB/M013278/1, BB/R017972/1) and the UK NIHR University College London Hospitals Biomedical Research Centre.

Author contributions: R.R.M. and B.V. conceptualized the review. R.R.M. wrote the original draft and prepared the figures. Both R.R.M. and B.V. reviewed and edited the final manuscript version.

Competing interests: B.V. is a consultant for Karus Therapeutics (Oxford, UK), iOnctura (Geneva, Switzerland) and Venthera (Palo Alto, US) and has received speaker fees from Gilead (Foster City, US). 
Fig. 1. Simplified schematic of canonical class IA PI3K signaling and cellular outputs.

5 Class IA PI3Ks exist as heterodimers composed of one of three catalytic subunits $(\mathrm{p} 110 \alpha, \beta$ or

$6 \delta$ ) bound to one of five regulatory subunits. They are commonly activated downstream of

7 receptor tyrosine kinases (RTKs) when the regulatory subunit binds to phosphorylated tyrosine

8 residues on the cytoplasmic domain of the receptor itself or associated adaptor proteins. The

9 activation of individual PI3K isoforms may be enhanced further by RAS (PI3K $\alpha, \mathrm{PI} 3 \mathrm{~K} \delta$ ),

RAC/CDC42 (PI3K $\beta)$ and/or G protein-coupled receptors $(\mathrm{PI} 3 \mathrm{~K} \beta)$. Once activated, class IA

PI3Ks catalyse the formation of the second messenger phosphatidylinositol- $(3,4,5)$ trisphosphate ( $\left.\mathrm{PIP}_{3}\right)$ which signals by binding to and recruiting effector proteins containing pleckstrin homology $(\mathrm{PH})$ domains. Among these effectors, the AKT isoforms (AKT1/2/3) are involved in orchestrating key PI3K-dependent cellular phenotypes by acting on myriad of cellular substrates, with some of the best characterised examples illustrated. These substrates also receive input from other pathways, and thus the final phenotypic output is determined by context-dependent signal integration. Feedback loops are omitted for clarity.

Fig. 2. Information transmission in cell signaling. Cells can respond to a signal's rate (A) and duration (B); they can also respond to a signal's strength (C) (amplitude modulation; AM), or a signal's temporal on/off pattern (D) (frequency modulation; FM)15,16. Conversely, cells may also use similar changes in the dynamic activity of a shared set of intracellular components to encode the identity of the upstream stimulus. (E) Example of low fidelity signal transmission in cells with oncogenic RAS/ERK pathway activation. Altered dynamics in cells with an oncogenic BRAF variant result in misinterpretation of the upstream signal (adapted from 
1 Ref.22). Similar corruption of information transmission, caused by enhanced BRAF-CRAF

2 dimerization, has also been observed in response to the BRAF inhibitors SB590885 and

3 Vemurafenib22.

4

5 Fig. 3. PIP3 dynamics encode distinct cellular responses. Using 3T3-L1 adipocytes

6 stimulated with platelet-derived growth factor (PDGF) or insulin, Tengholm and Meyer were

7 the first to demonstrate that cells may use different patterns of $\mathrm{PIP}_{3}$ dynamics to encode the

8 identity of the upstream growth factor, and subsequently decode these dynamics into different

9 responses. Thus, insulin but not PDGF triggers translocation of intracellular GLUT4-storage

10 vesicles to the plasma membrane and subsequent glucose uptake 44.

Fig. 4. Examples of dynamic information transmission in the class IA PI3K signaling

pathway. (A) In the PC12 rat pheochromocytoma cell line, different patterns of epidermal growth factor receptor (EGFR) stimulation are transmitted differently to S6 kinase (S6K) downstream of AKT activation. Strong but transient EGFR stimulation is not transmitted efficiently from AKT through mTORC1 and S6K, representing a case of decoupled signal transfer where the magnitude of the downstream response is opposite to that of the upstream signal (Box 1). Instead, downstream S6 phosphorylation occurs most potently in response to weak but sustained EGFR activation. The EGFR kinase inhibitor lapatinib (dashed red arrow) - by changing the dynamics of EGF-induced EGFR phosphorylation and activation paradoxically enhances S6 phopshorylation. Adapted from Ref.57. (B) Insulin levels in the blood oscillate according to specific patterns. These dynamic insulin changes are transmitted through phosphorylation of the insulin receptor (IR) and PI3K/AKT activation. Downstream, the different patterns of stimulation are selectively decoded through S6 kinase (S6K) and glycogen synthase kinase 3 (GSK3) phosphorylation as well as changes in glucose 6 phosphatase (G6P) gene expression40,60. As a result, the activity of each component is in tune 
with different aspects of the upstream signal in order to elicit the most appropriate

2 physiological response to insulin. Adapted from Ref.60.

3

4

5

\section{Fig. 5. Synthetic biology tools used in quantitative studies of PI3K signaling dynamics.}

(A) A reversible, chemically-induced dimerization (CID) system used to modulate class IA PI3K signaling. It relies on the expression of a synthetic inter-SH2 construct of p85 interacting with the p110 catalytic subunit in an isoform-agnostic manner141. Dimerization is induced by rCD1, a synthetic moiety that binds both to the SNAP tag at the plasma membrane and an FKBP fusion protein in the cytoplasm. The interaction can be reversed by addition of FK506 or an inert rapalog, both of which compete for binding to FKBP. (B) One of the first PI3K optogenetic (light-inducible) systems relied on the reversible light-induced interaction between phytochrome-interacting factor (PIF) and phytochrome (PHY) 142. Several other light-inducible PI3K systems have subsequently become available 143,144 . Note that both current CID and optogenetic approaches inevitably perturb the endogenous stoichiometry between p85 and p110, with likely consequences for downstream signaling output5,145. (C) The principle behind commonly used genetically-encoded $\mathrm{PIP}_{3} / \mathrm{PI}(3,4) \mathrm{P}_{2}$ biosensors. Different $\mathrm{PH}$ domain may bind either one or both lipid species, leading to translocation of the fluorescent reporter from the cytosol to the plasma membrane (for a comprehensive review on these sensors, see Ref.66). (D) Fluorescent FOXO-based nucleocytoplasmic translocation reporters are commonly used in dynamic single-cell studies of PI3K signaling64,146-148. Note, however, that FOXO proteins are only responsible for a subset of PI3K-dependent phenotypes 149.

Fig. 6. The context-specific PI3K signaling 'tune'. Similar to the melody from an accordion, the output of PI3K signaling is shaped by the integration of multiple input parameters. AM, amplitude modulation. FM, frequency modulation. 


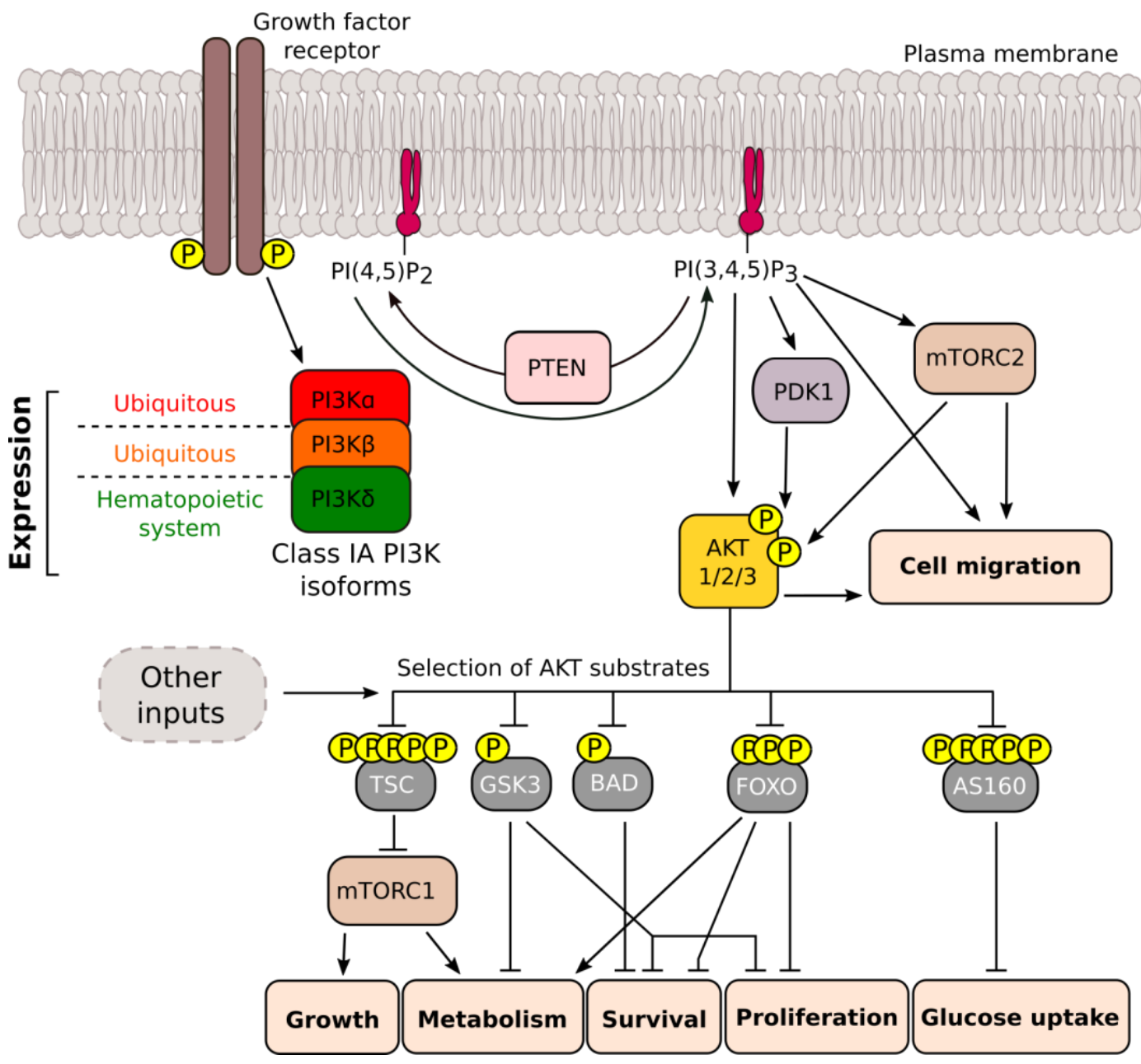

Figure 1 
A Response to signal rate

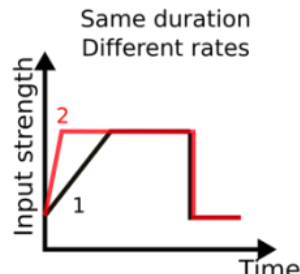

Different durations ᄃA Same rates
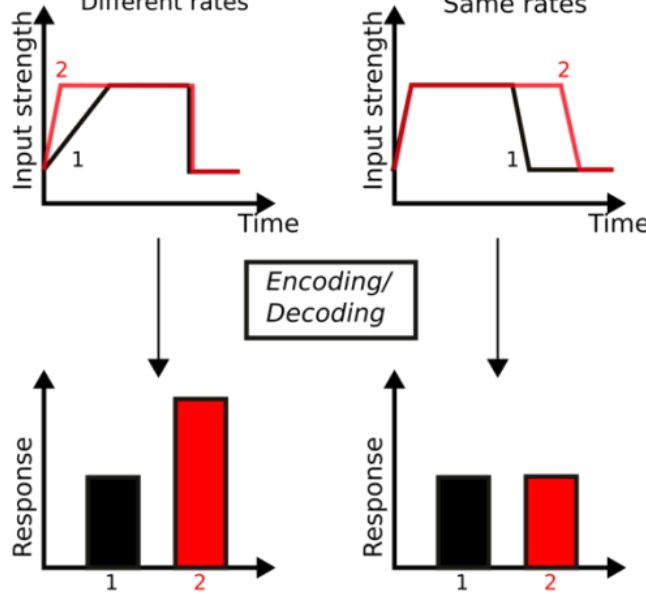

Encoding/

Decoding

C

Response to amplitude modulation
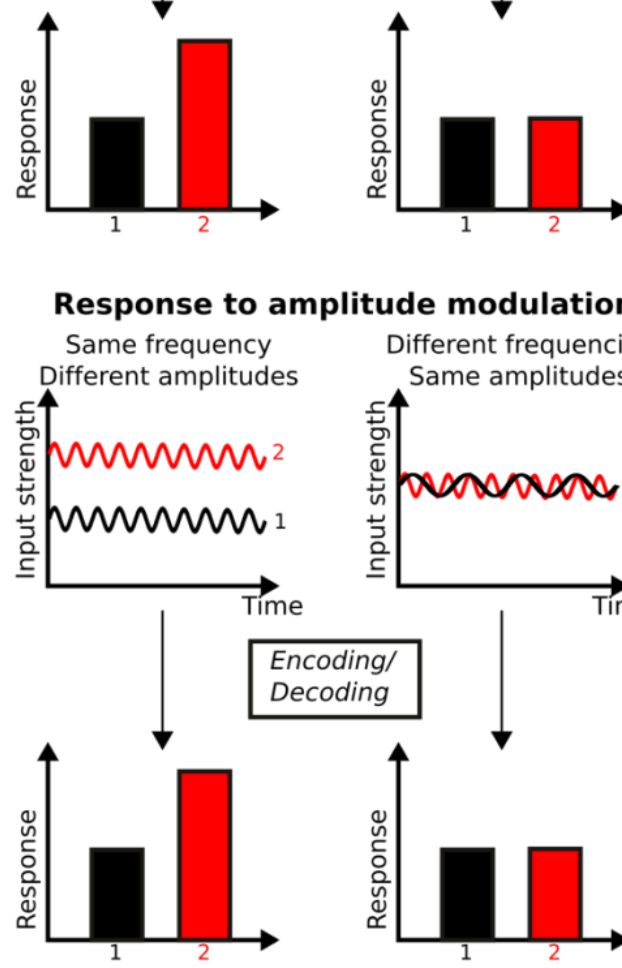

Different frequencies Same amplitudes
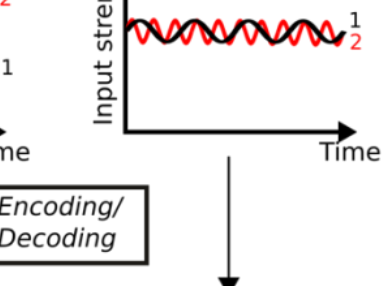

E

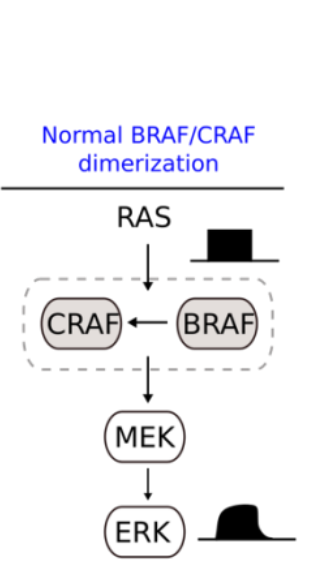

Fast signaling decay

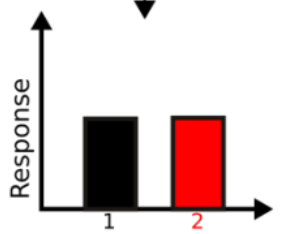

D

Response to signal duration

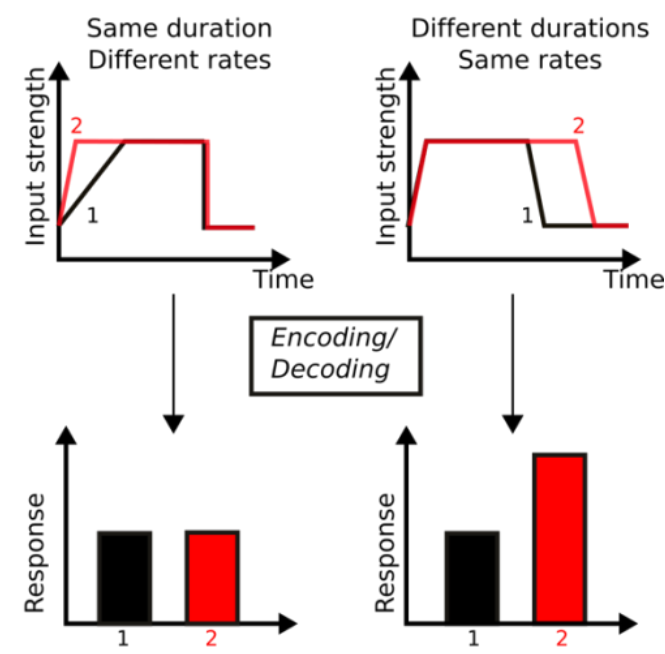

Response to frequency modulation

Same frequency
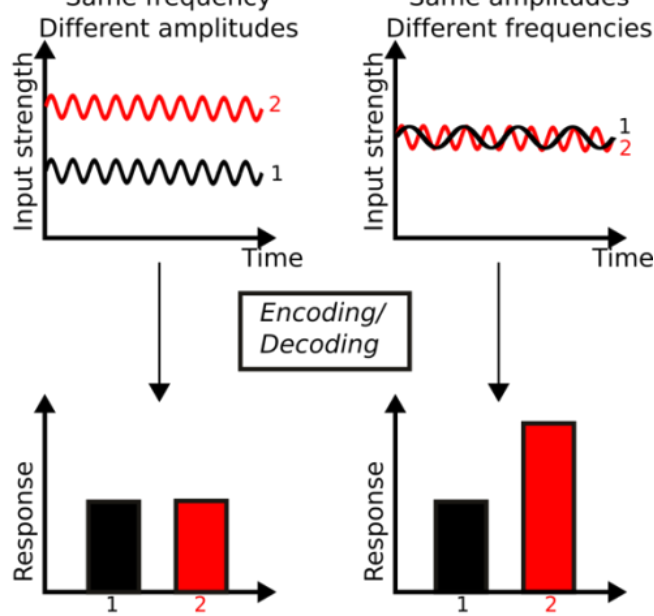

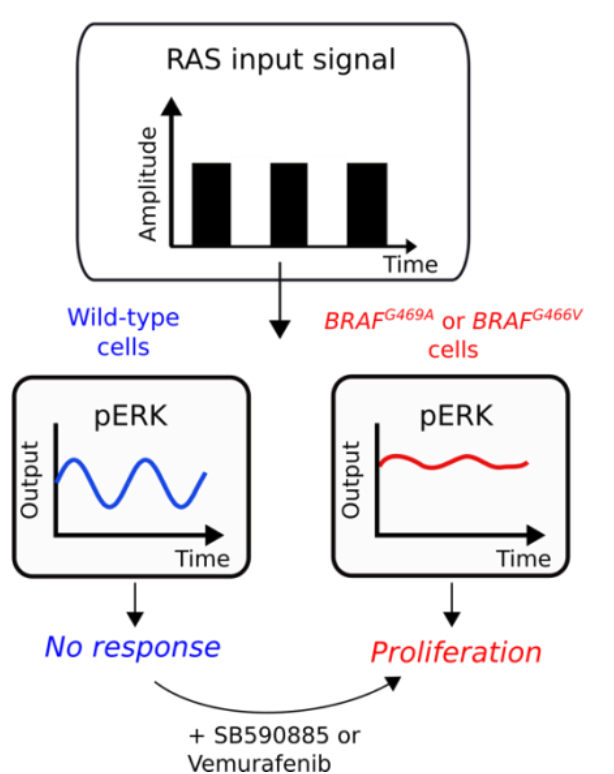

Figure 2

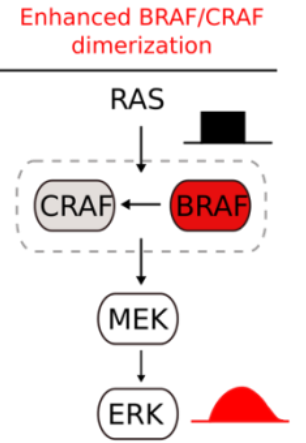

Slow signaling decay 


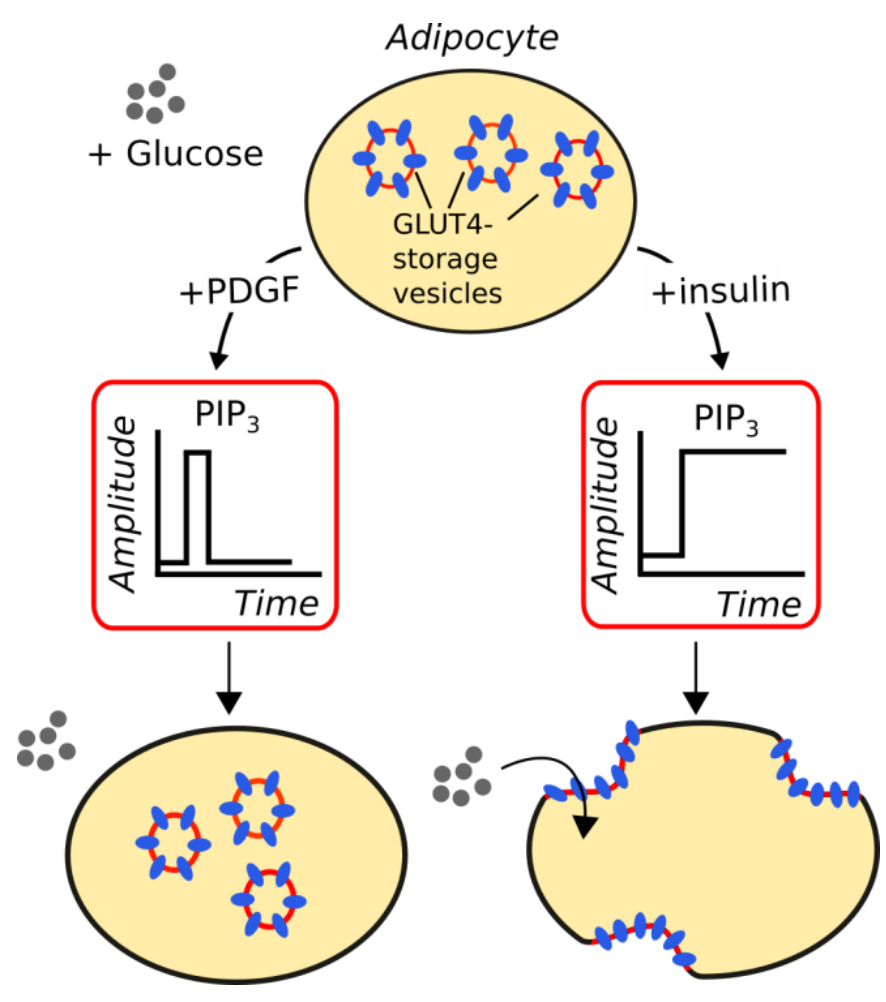

Figure 3 
A

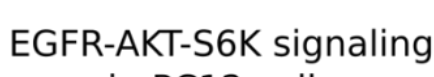

in $\mathrm{PC} 12$ cells

(Fujita et al. 2010)

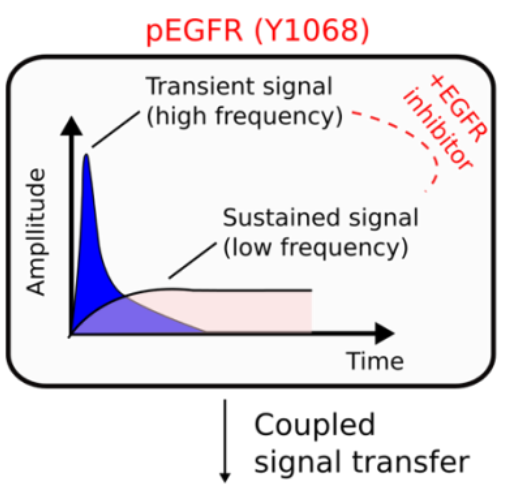

pAKT (S473)

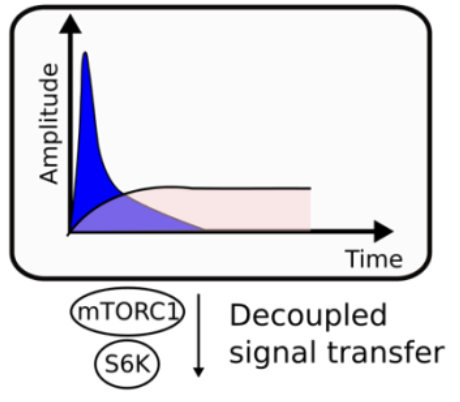

pS6 (S235/S236)

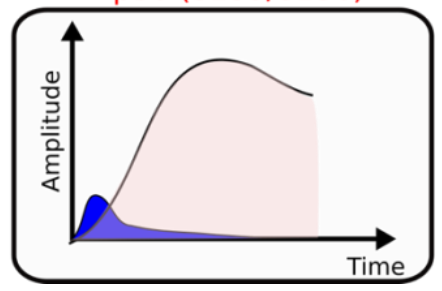

B

Decoding of insulin dynamics

(Kubota et al. 2012, 2018)

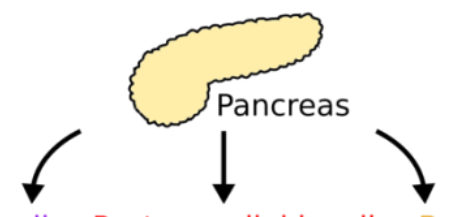

Pulsatile insulin Post-prandial insulin Basal insulin secretion secretion secretion (15 minutes) (2 hours) (24 hours)

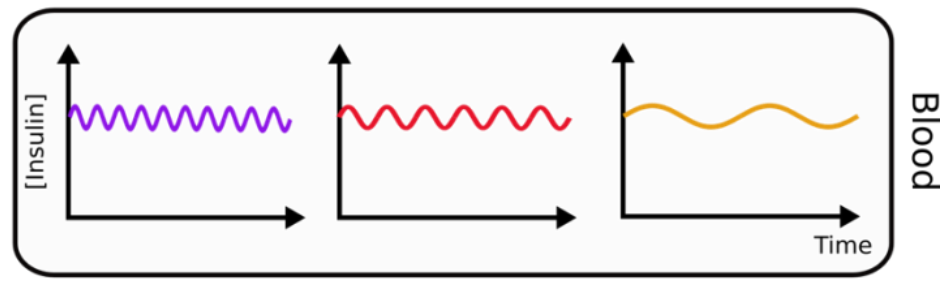

PI3K pathway activation

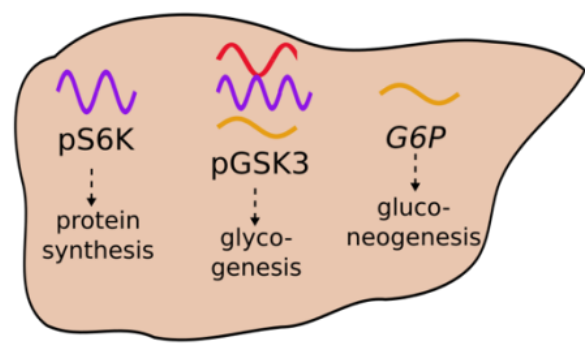

Hepatic demultiplexing of blood insulin dynamics and decoding into distinct phenotypes

\section{Figure 4}


A Chemically-induced dimerization (CID)
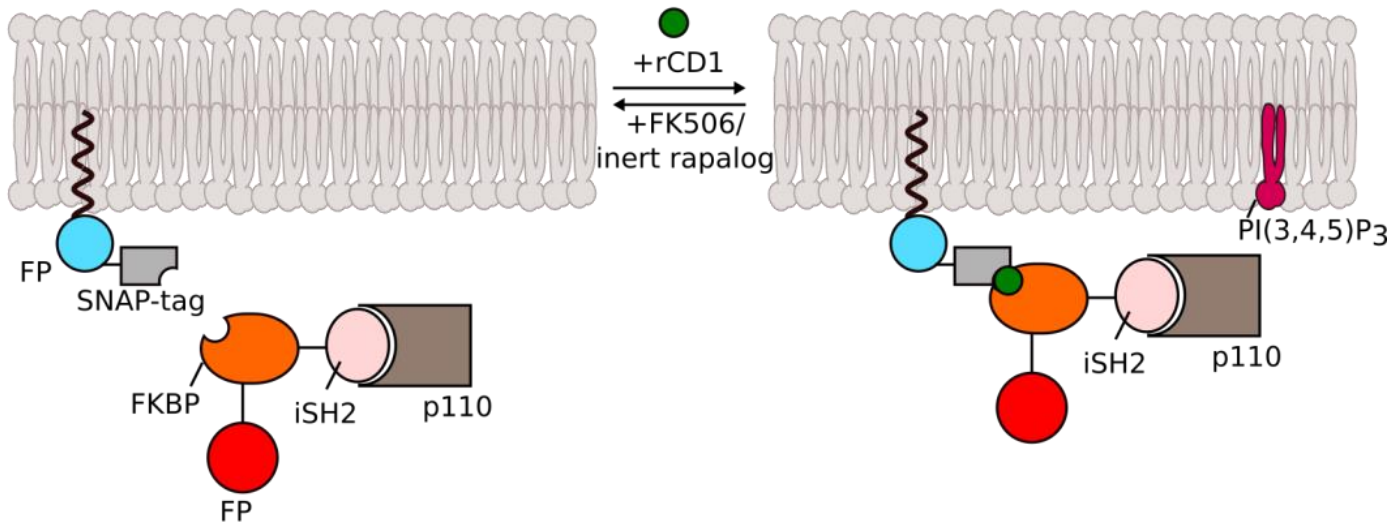

B

Optogenetics: light-induced dimerization
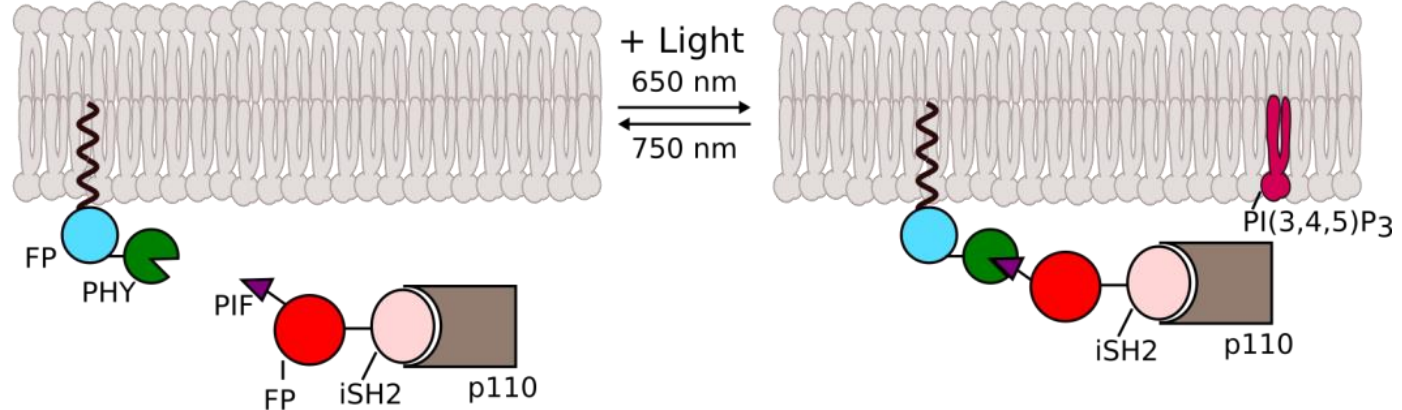

C

Fluorescent $\mathrm{PIP}_{3}$ reporter

D Fluorescent FOXO1 reporter
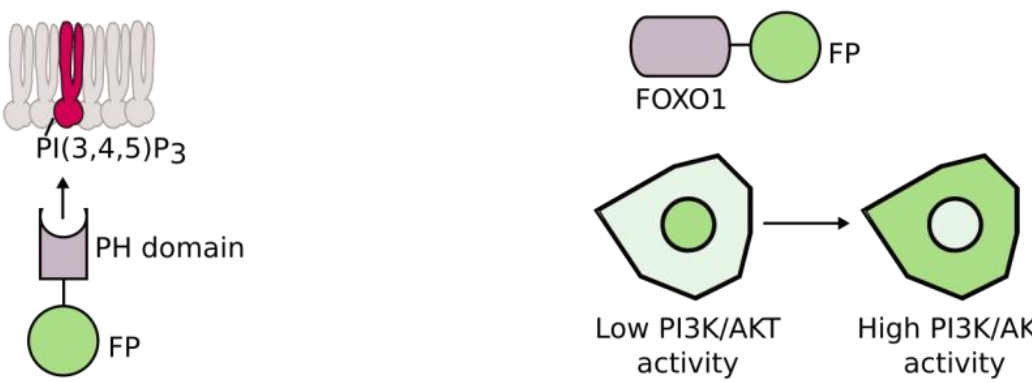

Low PI3K/AKT High PI3K/AKT activity activity

Figure 5 


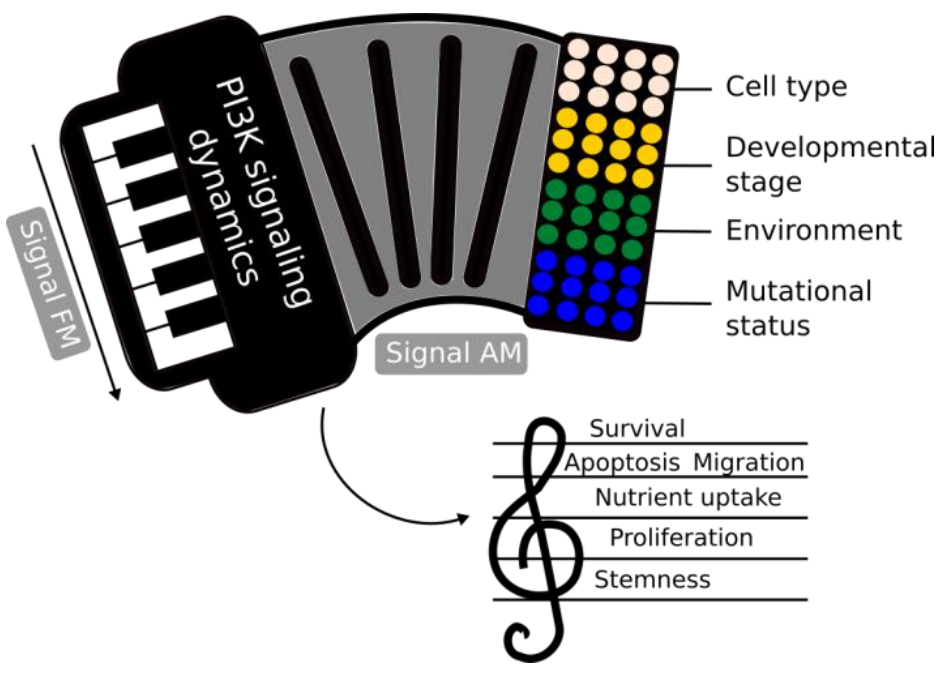

Figure 6 